Review Paper

\title{
Kick detection and remedial action in managed pressure drilling: a review
}

\author{
Mohammad Mojammel Huque ${ }^{1} \cdot$ Syed Imtiaz ${ }^{1} \cdot$ Aziz Rahman $^{2} \cdot$ Mohamed Hossain $^{3}$
}

Received: 27 January 2020 / Accepted: 27 May 2020 / Published online: 6 June 2020

(c) Springer Nature Switzerland AG 2020

\begin{abstract}
Increasing the global demand for natural resources directs the oil industries to explore in geologically challenging structures and offshore reserves. Oil industries are always searching for innovative drilling technologies to optimize field development process in a complex structure. Managed pressure drilling (MPD) is now becoming an attractive alternative to the traditional overbalance drilling in complex formation. MPD offered substantial benefits in terms of project economics and reduced non-productive time (NPT). These benefits are substantial in the offshore structure, where any downtime significantly impacts the project cost. MPD is designed to avoid continuous formation influx into the wellbore, and any incidental fluid is contained with a specific predetermined process. MPD used some specialized tools and techniques to enhance traditional kick detection capabilities and circulate formation influx while keeping NPT at the minimum level. Early kick detection is a primary concern for the drilling industry to ensure the safety of the drilling rig, crews, and environmental protection. This research focused on a systematic review of kick detection and mitigation in MPD operation. A review of recent advancements in MPD, various early kick detection methods, comparative study of different kick indicators with their significance, different gas kick models, and risk analysis are analyzed systemically. Several control methods in the MPD operation are summarized. A systematic comparison of different gas kick circulation methods in conventional drilling and MPD is presented in this study. Also, different alternative responses to conventional kick circulation methods are summarized. This work critically analyzed different kick responses of circulating and non-circulating methods, e.g. shut-in, modified pump shut down, increasing in casing pressure and stepwise increase in pump rate. However, all circulation methods are elementary, and no kick circulation method is universally applicable to all drilling operations. Finally, this review emphasized some recent progress and challenges in kick detection on managed pressure drilling.
\end{abstract}

Keywords MPD · Early kick detection $\cdot$ Kick response $\cdot$ Well control

\begin{tabular}{|c|c|c|c|}
\hline \multicolumn{2}{|l|}{ List of symbols } & $f$ & Friction factor \\
\hline$\lambda$ & Gas void fraction & $F_{g}$ & Frictional cross section area available to \\
\hline$\phi$ & Wave scattering variable & & gas \\
\hline$a_{g}$ & Speed of sound in gas $=316 \mathrm{~m} / \mathrm{s}$ & $g$ & Acceleration due to gravity $\left(9.8 \mathrm{~m} / \mathrm{s}^{-2}\right)$ \\
\hline $\begin{array}{l}a_{1} \\
C\end{array}$ & $\begin{array}{l}\text { Speed of sound in liquid }=1500 \mathrm{~m} / \mathrm{s} \\
\text { Sonic velocity }\end{array}$ & $h_{G}$ & $\begin{array}{l}\text { Distance of the bubble head to the of the } \\
\text { riser }\end{array}$ \\
\hline$C_{A}$ & Annular capacity & $K$ & Distribution coefficient \\
\hline$C_{0}$ & Distribution factor & $M_{G}$ & Mass of the gas bubble $(\mathrm{kg})$ \\
\hline$C_{i}, C_{1}, C_{2}, C_{3}$ & Coefficient & $M W_{\text {surface }}$ & Mud weight at surface \\
\hline & Pipe diameter & $P_{G}$ & Pressure in the gas bubble (psi) \\
\hline
\end{tabular}

Mohammad Mojammel Huque, mmh710@mun.ca| ${ }^{1}$ Memorial University of Newfoundland, St. John's, Canada. ${ }^{2}$ Texas A\&M University at Qatar, Doha, Qatar. ${ }^{3}$ The American University in Cairo, New Cairo, Egypt. 


$P_{\text {pump }}$
$P_{g o}$
$P_{s}$
$P_{c s i}$
$P_{B H P}$
$\Delta P_{\text {Hydrostatic }}$
$\Delta P_{\text {Friction }}$
$P_{\text {choke }}$
$Q_{I}$
$Q_{g}$
$Q_{\text {in }}$
$Q_{\text {out }}$
$Q_{\text {pump }}$
$S$
$t$
$V_{f}$
$V_{G}$
$V_{g o}$
$V_{m}$
$V_{\text {mud }}$
$V_{\text {borehole }}$
$V_{w}$
$V_{m}$
$V_{c}$
$V_{t}$
$W_{\text {drillstring }}$
$X_{m}$
$Z$
$Z$

$\begin{array}{ll}\text { Abbreviations } & \\ \text { BOP } & \text { Blow out preventer } \\ \text { BHP } & \text { Bottomhole pressure } \\ \text { CBHP } & \text { Constant bottom hole pressure } \\ \text { CFD } & \text { Computational fluid dynamics } \\ \text { ECD } & \text { Equivalent circulation density } \\ \text { HPHT } & \text { High-pressure high-temperature } \\ \text { IADC } & \text { International association of drilling } \\ & \text { contractors } \\ \text { MPD } & \text { Managed pressure drilling } \\ \text { MW } & \text { Mud weight } \\ \text { MWD } & \text { Measurement while drilling } \\ \text { OBM } & \text { Oil based mud } \\ \text { ODM } & \text { Original drilling mud } \\ \text { PTP } & \text { Pressure transfer parameter } \\ \text { RCD } & \text { Rotating control device } \\ \text { SBM } & \text { Synthetic-based mud } \\ \text { UBD } & \text { Underbalanced drilling } \\ \text { WCM } & \text { Well control matrix } \\ \text { WHP } & \text { Wellhead pressure }\end{array}$

Initial average gas pressure (psi)

Surface pressure (psi)

Shut in casing pressure (psi)

Botthomhole pressure (psi)

Hydrostatic pressure drop (psi)

Frictional pressure drop (psi)

Choke pressure (psi)

Liquid rate (bbl/min)

Gas rate (scf/min)

Mud inflow rate

Mud outflow rate

Pump flow rate

Distribution coefficient

Time (s)

Filtrate loss volume (bbl)

Injected volume of gas (scf)

Mud volume (bbl)

Mud volume

Borehole volume

Well volume (bbl or cubic $\mathrm{ft}$ )

Mud velocity (ft/s)

Circulated fluid volume (bbl)

Taylor bubble rise velocity $(\mathrm{ft} / \mathrm{s})$

Weight of the drill string

Mud compressibility (1/psi)

Spatial coordinate variable

Axial position

\section{Introduction}

Velocity of the gas bubble head $(\mathrm{ft} / \mathrm{s})$

Drilling mud is designed to maintain the wellbore pressure higher than the pore pressure boundary and lower than the fracture pressure boundary to avoid any formation influx into the wellbore. This boundary is known as the drilling window. In conventional drilling, a slightly overbalanced environment is preserved to prevent any formation influx. This overbalance condition is reasonable when an extensive range of pore pressure and fracture pressure is available. However, the applicability of the conventional drilling method is very limited in a complex formation or depleted reservoir due to narrow drilling window. This limitation widens the scope of managed pressure drilling (MPD) for complex geological structures. The concept of MPD derived from the forbear technology underbalanced drilling where minor formation influx deliberately allowed to avoid formation damage. MPD technology utilizes every measurement to avoid continuous formation influx, and any incidental flow is carefully controlled with the appropriate process. The International Association of Drilling Contractors (IADC)'s Underbalanced Operations and Managed Pressure Committee has defined "managed pressure drilling (MPD) is an adaptive drilling process used to precisely control the annular pressure profile throughout the wellbore. The objectives are to ascertain the downhole pressure environment limits and to manage the annular hydraulic pressure profile accordingly." [86].

MPD is a relatively new technology to the petroleum industry but recognized as a proven drilling method in the last 15 years. MPD offers not only reduced non-productive time (NPT) but also enables to drill in the crucial geological formation that previously considered as unreliable with available technology. In recent years, MPD has implemented into the different geological regions, e.g. the Asia Pacific, Middle East, Europe, Gulf of Mexico, Russia, and Africa [4, 11, 14, 26, 29, 75, 144, 159, 185]. MPD is also productively implemented in the HPHT wells [26, $67,164,167]$ and fractured carbonate formation [133]. Field application shows that MPD operation successfully mitigates different drilling problems, e.g. lost circulation $[136,145]$, wellbore instability $[50,208]$, stuck pipe [11, $126,136]$, wellbore control issue [122] and significantly reduce the non-productive time. MPD process utilizes a set of tools and techniques that mitigate the risk and cost associate with drilling in a narrow pressure window by precisely controlling the annular pressure profile in the wellbore. Failure to maintain the narrow drilling pressure profile often causes a kick.

During any drilling operation, if the bottom hole pressure is less than formation pressure; formation fluid such 
as gas or any other fluid, may enter the wellbore. This influx of formation fluid invasion into the wellbore is known as a kick. Early detection of a kick is a primary concern for the drilling industry to ensure a safe drilling operation, workers' safety, and environmental protection. A late kick detection may cause an uncontrolled blowout, which leads to a higher risk of injury of drilling personnel, catastrophic to drilling facility, potential loss of well and natural resources as well as adversely impacts on the project economics.

Both lab-scale $[30,110,112,165,189]$ and field study $[74,80]$ show different early kick detection methods, risk assessment $[113,158,202]$ and mitigation system [210]. The effectiveness of kick management largely depends on the prompt detection of a kick and size of the kick when detected. A manual kick detection system depends on the drilling crew's competence, expertise and data interpretation skills that might be inconsistent and inefficient at different drilling environments. However, an automated kick detection system offers robust control on the equipment, consistent data acquisition and intelligent control and quick response to any incidental situation. Since managed pressure drilling works in a very narrow drilling window, any pressure fluctuation within this narrow margin due to a kick can be quickly detected. Once the kick is detected, MPD can promptly control the well at minimum kick size before it initiates a threat to the well integrity. MPD precisely control the annular pressure while circulating the kick out of the hole without shutting the well.

In MPD operation, well control shows a significant advancement over a conventional system. Traditional well control methods rely on fundamental approaches like pit gain at the surface, pump pressure variation for any incoming kick and 'shut in the well' is the only approach to control a well during an unwanted situation. However, there are several alternative responses available with $M P D$, such as increasing casing pressure, reviewing the pump rate without shutting the well or controlling the mud return rate with a surface choke, etc. These alternative approaches in MPD significantly reduce the response time to kick, NPT, cost, and most importantly provide a safer drilling operation. In MPD operation, this secure handling of gas kick supported by precise control of the drilling parameters like surface backpressure, bottomhole pressure, mud circulation rate etc. So, a very sophisticated control system is essential in a managed pressure drilling system.

Several field studies $[20,52,85,93,122,126]$ show the important aspects of well control in MPD operation. Besides the field studies, researchers also demonstrate several well control studies $[19,45,69,83,100,115,129,130]$ that describe the MPD kick management and different well control scenarios based on kick behaviour. These studies also focused on the dynamic kick management of a managed pressure drilling system. With a well-defined control system, MPD can effectively circulate the kick out of the hole without shutting the well by adequately adjusting the surface backpressure and maintaining an appropriate fluid circulation rate.

There are numerous studies on various aspects of MPD, such as MPD field application, control mechanism, kick identification, risk analysis, decision tree and kick management system etc. available in the literature. However, a comprehensive review of kick detection and kick response in MPD operation is still missing in the literature. This lacking motivated the authors for a comprehensive review of gas kick, kick detection and kick response in MPD operation. The authors also reviewed different well control methods for a constant bottomhole pressure MPD operation.

This manuscript organized as follows: Sect. 2 covers an overview of MPD technology, MPD variant and MPD operating principles. Section 3 describes a detail about the reason for a kick, early kick warning signs and different kick identification methods. Review of gas kick modelling, simulation, and control system of the MPD are presented in Sect. 4. Section 5 shows the different responses of gas kick, risk evaluation and well control matrix. Section 6 covers a review of some recent advancement in MPD operation, including machine learning, computational fluid dynamics, and list some scopes of the further research area in MPD. Finally, Sect. 7 covers a conclusion of this study.

\section{Managed pressure drilling compared with conventional drilling method}

Drilling methodologies vary with drilling objectives that largely depend on formation characteristics. In conventional overbalanced drilling, the focus is to avoid formation influx and accomplished by maintaining bottomhole pressure above the formation pressure. As a result, this causes formation damage to some extent and does not mitigate any problems of pressure instability. In MPD, the bottomhole pressure is kept nearly equivalent to the formation pressure. Variable surface backpressure is applied to control bottomhole pressure precisely during drilling and keep it in a static condition. Furthermore, MPD can handle pressure related problems like wellbore instability, differential sticking etc. Table 1 shows a comparative analysis of vital key variables about various drilling methods. In conventional drilling, bottomhole pressure (BHP) is achieved by mud weight (MW) and annular frictional pressure. However, in managed pressure drilling, an additional control parameter called 'backpressure' is applied to control the bottomhole pressure. This 'backpressure' 
Table 1 Analysis of different drilling methods

\begin{tabular}{|c|c|c|c|c|c|c|}
\hline \multirow[t]{2}{*}{ Drilling methods } & \multicolumn{3}{|c|}{ Minimization and control of } & \multirow[t]{2}{*}{ Pressure scenario } & \multicolumn{2}{|l|}{ BHP control } \\
\hline & $\begin{array}{l}\text { Forma- } \\
\text { tion } \\
\text { influx }\end{array}$ & $\begin{array}{l}\text { Formation } \\
\text { damage }\end{array}$ & $\begin{array}{l}\text { Pressure } \\
\text { related } \\
\text { problem }\end{array}$ & & During drilling & Static condition \\
\hline Overbalanced drilling & $\sqrt{ }$ & $X$ & $\mathrm{X}$ & $P_{B H P}>P_{r}$ & $\mathrm{BHP}=\mathrm{MW}+\mathrm{ECD}$ & $\mathrm{BHP}=\mathrm{MW}$ \\
\hline Managed pressure drilling & $\sqrt{ }$ & $\sqrt{ }$ & $\sqrt{ }$ & $P_{B H P} \cong P_{r}$ & $\begin{array}{l}\mathrm{BHP}=\mathrm{MW}+\mathrm{ECD}+\text { back- } \\
\text { pressure }\end{array}$ & $\mathrm{BHP}=\mathrm{MW}+$ backpressure \\
\hline
\end{tabular}

$\sqrt{ }$ yes, $\mathrm{X}$ no, $E C D$ equivalent circulating density, $M W$ mud weight, $B H P$ bottomhole pressure

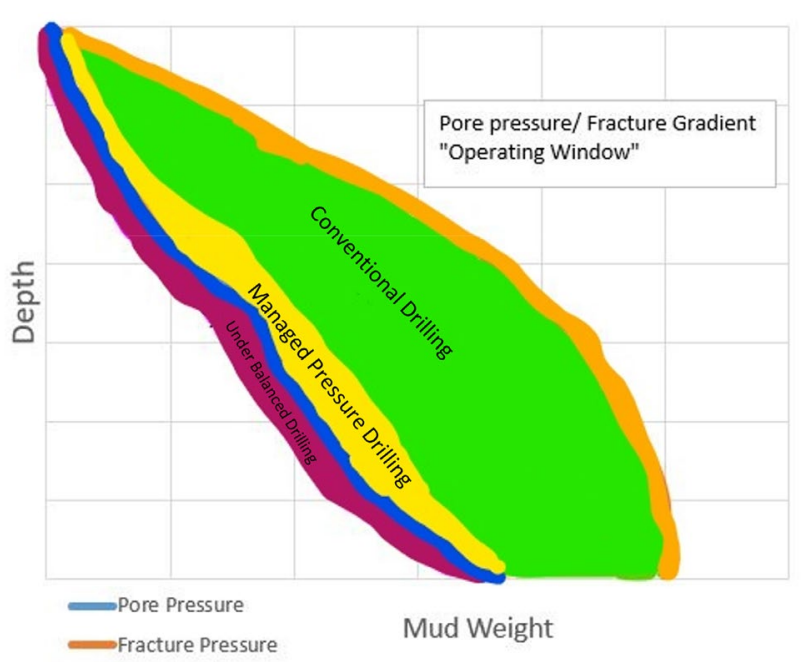

Fig. 1 A hypothetical pore pressure gradient and fracture pressure gradient envelope. Redrawn from Stone and Tian [176]

provides a wide range of pressure control. Thus, wellbore pressure remains steady irrespective of the reservoir conditions [194].

Mathematically bottomhole pressure can be expressed as

$P_{\text {Reservoir }} \cong P_{\text {BHP }}=\Delta P_{\text {Hydrostatic }}+\Delta P_{\text {Friction }}+P_{\text {choke }}$.

\subsection{Managed pressure drilling operating envelope}

MPD aims to keep bottomhole pressure within prescribed limits and achieve a narrow annular pressure outline accordingly. This slim pressure envelope is due to the geological structure of the reservoir, especially in the offshore, carbonate rock shows a very narrow pressure window. Figure 1 shows a hypothetical pore pressure gradient versus fracture pressure gradient envelope.

Figure 1 indicates that MPD has a very narrow drilling window that needs to maintain throughout the drilling operation. This narrow window is obtained by controlling wellhead pressure or surface backpressure, drilling mud density and mudflow rate. Generally, drillers set the operational and environmental variables like mud density, mud pump rate, casing pressure and rate of penetration. These pre-set variables keep the wellbore pressure slightly above or at balance or near balance with the bottomhole pore pressure. A precise wellbore pressure control allows a driller to work within the narrow margin of fracture pressure and pore pressure.

\subsection{Variants in managed pressure drilling}

There are three significant variations available in managed pressure drilling based on operating condition. Table 2 shows major MPD variants with their scopes. Each method has its objective regarding pressure control and influx management. In "Constant Bottomhole Pressure" method, bottomhole pressure is controlled by automatic adjusting the choke to track the pre-defined pressure trajectory. The primary goal of the controller is to eliminate any kick or fluid loss when a fracture gradient is approaching pore pressure [140]. In offshore operations where the return mud does not travel through a large diameter drilling riser, the "Dual Gradient Drilling" method is the right choice. This method reduces the number of casings required in the deep-water marine environment. A mud cap and pressurized mud cap method with a sacrificial fluid are used to manage the mud losses in the highly depleted formation. Among these variants, constant bottomhole pressure drilling (CBHP) is the most common scenario for deep well drilling. As stated in its name, CBHP MPD maintains constant pressure at a certain depth of wellbore for a mud weight. The mud pump rate can be changed to maintain a constant wellbore pressure at any operating condition, whether it is static or dynamic [45].

CBHP MPD uses the procedure of adjusting the mudflow rate and surface backpressure to circulate a small to medium-sized kick out of the well safely and efficiently without shutting the well [95]. Table 3 listed some essential features in terms of kick handling of conventional and CBHP MPD methods. A comparison shows that the CBHP 
Table 2 MPD variants with their objectives

\begin{tabular}{llll}
\hline MPD variants & $\begin{array}{l}\text { Constant bottomhole } \\
\text { pressure (CBHP) }\end{array}$ & $\begin{array}{l}\text { Dual gradient drill- } \\
\text { ing (DGD) }\end{array}$ & $\begin{array}{l}\text { Pressurized } \\
\text { mud cap drilling } \\
\text { (PMCD) }\end{array}$ \\
\hline Unknown drilling window & $\sqrt{ }$ & $\mathrm{X}$ & $\mathrm{X}$ \\
Slow ROP & $\sqrt{ }$ & $\mathrm{X}$ & $\mathrm{X}$ \\
Severe loss of circulation & $\mathrm{X}$ & $\mathrm{X}$ & $\sqrt{ }$ \\
Sour formation & $\mathrm{X}$ & $\mathrm{X}$ & $\sqrt{ }$ \\
Avoid gross overbalance & $\mathrm{X}$ & $\sqrt{ }$ & $\mathrm{X}$ \\
Ballooning problem & $\sqrt{ }$ & $\mathrm{X}$ & $\mathrm{X}$ \\
Well control risk & $\sqrt{ }$ & $\mathrm{X}$ & $\mathrm{X}$ \\
\hline
\end{tabular}

$\sqrt{ }$ yes, $X$ no
Table 3 Key differences between conventional drilling versus CBHP MPD

\begin{tabular}{lll}
\hline Key features & $\begin{array}{l}\text { Conven- } \\
\text { tional } \\
\text { drilling }\end{array}$ & CBHP MPD \\
\hline Surface backpressure applied & $\mathrm{X}$ & $\sqrt{ }$ \\
Maintain a constant bottomhole pressure & $\mathrm{X}$ & $\sqrt{ }$ \\
Prompt kick identification & $\mathrm{X}$ & $\sqrt{ }$ \\
Find unwanted flux in the system & $\mathrm{X}$ & $\sqrt{ }$ \\
Support alternative method of well & $\mathrm{X}$ & $\sqrt{ }$ \\
$\quad$ control & & \\
\hline
\end{tabular}

$\sqrt{ }$ yes $X$ no

MPD method outperforms the traditional methods in terms of well control, pressure, and influx management during the drilling operation. Therefore, this study focused on CBHP MPD operation.

Dynamic well control has a physical limit of the equipment in handling a gas kick due to the surface facility limitations, equipment integrity and safety concerns. A small gas influx in the bottomhole can be as high as 100 times of original volume at the surface. Influx size is a vital issue in offshore drilling, where kick fluid volume of fewer than ten barrels is desirable for the safe circulation of a kick [95]. Thus, there is a volumetric limit for all MPD setups that can handle a gas kick. For this reason, early detection of a gas kick is crucial for the safe operation of managed pressure drilling and well control. An early kick detection ensures the minimum kick size in the wellbore during kick circulation.

\subsection{MPD versus well control tools}

In conventional drilling, the required and actual bottomhole pressure varies based on the well circulation status. In contrast, both actual and required bottomhole pressure remains the same in MPD irrespective of well circulation, as shown in Fig. 2.
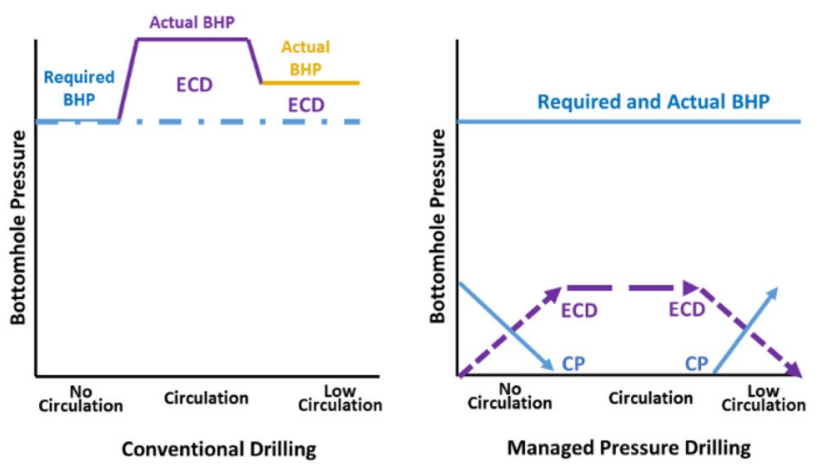

Fig. 2 Bottomhole pressure response versus drilling methods. Redrawn from Saponja et al. [163]

MPD prevents continuous circulation of influx to the surface. The goal is to maintain a constant bottomhole pressure and circulate kick with a suitable method such as Driller's methods. Ensuring the wellbore and equipment integrity during circulation prevents any flow from the formation [198]. When there is no flow, or at low the pump rate, the bottomhole pressure also tends to reduce, due to loss of the annular frictional pressure drop $\left(\Delta P_{\text {Friction }}\right)$. In the MPD system, this reduction in the frictional pressure drop component can be compensated by applying additional backpressure. It also adjusts the casing pressure to maintain a constant bottomhole pressure. When a mud pump's circulation restarts, the induced additional backpressure is reduced to increase the equivalent circulating density (ECD) of the system $[70,132,133]$. Though MPD can partially serve dynamic well control by manipulating parameters like surface backpressure, mud density and pump rate, however MPD is not an absolute well control method. By manipulating the choke, it is possible to control the influx from the well without shutting the well. However, MPD can handle a limited volume of kick and kick intensity that needs to be estimated in advanced. 


\subsection{Managed pressure drilling operating principle}

Figure 3 shows a typical arrangement of a typical MPD setup of CBHP. The strategic equipment of this control mechanism is a Rotating Control Device (RCD). The role of $\mathrm{RCD}$ is to control and divert upstream flow through choke manifold. It also maintains the annular isolation of the drill string and the well. The setup has the provision for working as MPD as well as conventional drilling since the outlet from the RCD can be diverted to the main flowline or MPD choke manifold.

MPD choke manifold is another critical component that enables variable flow restriction to maintain a constant bottomhole pressure at any operating condition. The primary purpose of the choke manifold is to control the well pressure, not the flow rate. Once an influx is detected, the choke is automatically adjusted to increase the surface backpressure to control the influx. Finally, it can be circulated out by mud gas separator through MPD manifold.

\section{Reservoir kick}

A kick initiates an uncontrolled flow of formation fluid towards the wellbore that dominates the well control to a state of emergency during a drilling operation. The kick may occur if a well is drilled in a hydrocarbon-bearing formation that has a higher pressure than the pressure of the wellbore, thus prompting the formation influx to flow towards the wellbore. Various types of formation fluids such as gases, hydrocarbons, oil, water, or any combination of different fluids can enter the wellbore during a kick. Among different formation fluid, a gas kick is more severe due to a dramatic expansion of the gas when it reaches the surface. A 10 years' statistics [200] showed that approximately $6 \%$ kicks occurred in exploratory wells, whereas this figure is around 3.2\% for development wells. For both categories, a kick is most likely to occur at a depth higher than $4000 \mathrm{~m}$. Holand and Awan [82] showed a statistical analysis of 576 wells from the Norwegian Continental Shelf, with 9\% kick in standard drilling, 32\% kick in deepwater drilling and $139 \%$ kick at HPHT well, as shown in Fig. 4.

\subsection{Reason for kick}

There are several reasons for the occurrence of a kick. The most important reason is the low wellbore pressure. Low wellbore pressure can occur in two ways:

1. Drilling mud weight is low compared to the anticipated weight A sudden mud density drop causes lower pressure in the wellbore, or the formation pressure becomes higher than anticipated. Thus, the hydro-

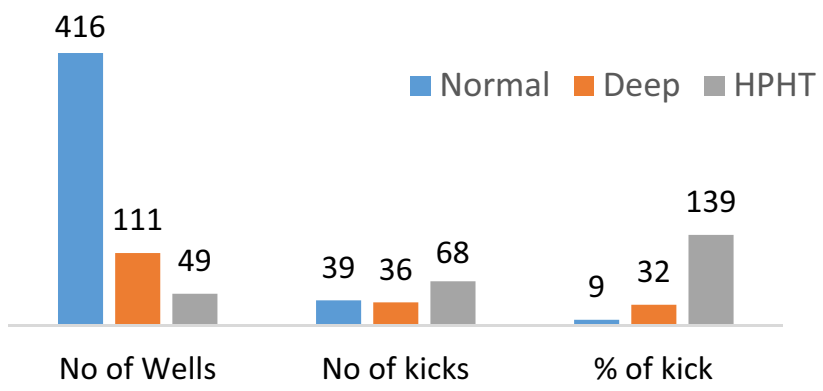

Fig. 4 Kick statistics for normal drilling, deep water drilling and HPHT drilling [82]

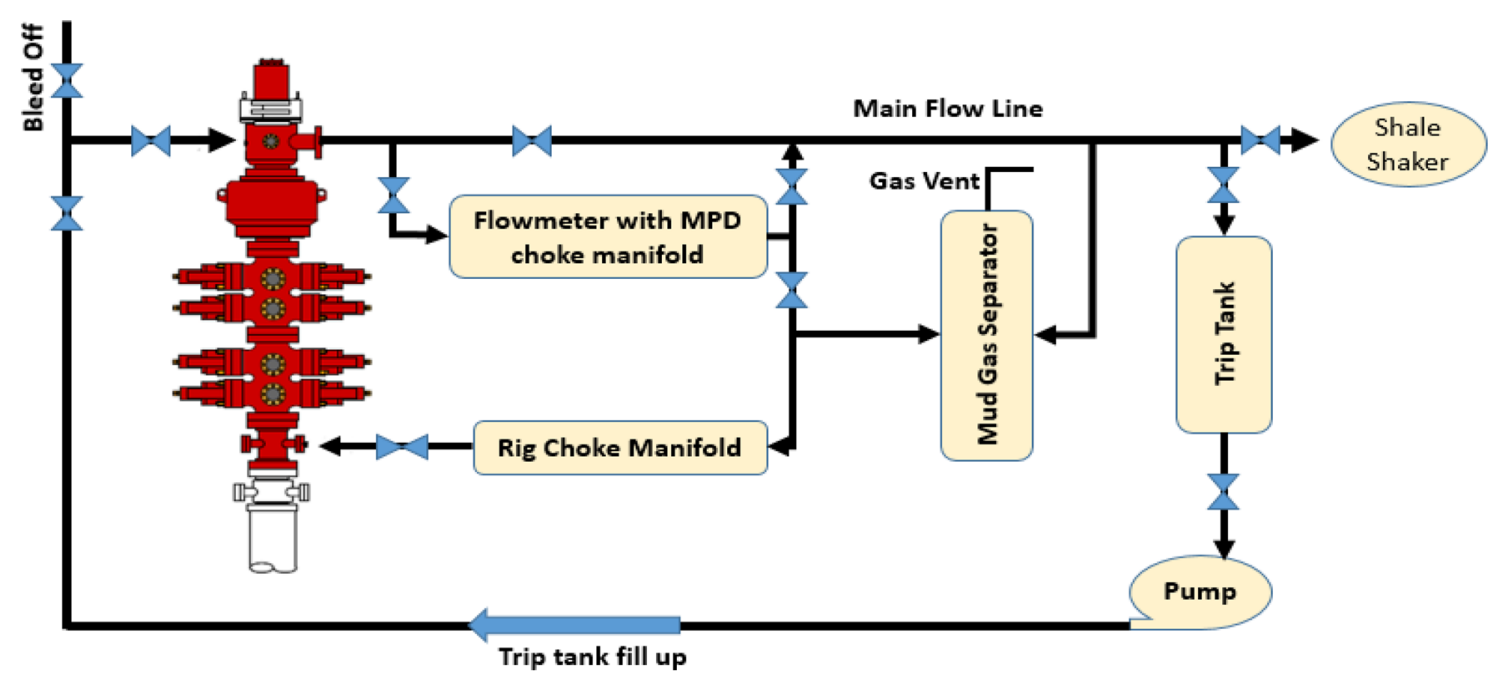

Fig. 3 MPD setup of a closed wellbore system. Adopted from Nas [131] 
static pressure applied by the mud weight is insufficient to counterbalance the formation pressure at the wellbore.

2. Dynamic and transient wellbore pressure condition The relative movement of the drill pipe during tripping in the wellbore causes a transient environment, which may also reduce the wellbore pressure compared to the pore pressure.

Apart from low wellbore pressure, formation and fluid characteristics are also closely related to kick. There are three primary conditions for a kick to occur [131]. They are:

1. Pressure inequality Exposed formation pressure is higher than the wellbore pressure.

2. Permeability The reservoir section of interest has a substantial permeability so that it can allow the influx fluid to flow into the wellbore; and

3. Viscosity The formation fluid has a low viscosity that enables a smooth flow into the wellbore.

Gas kick might also occur if the operator loses well control during a drilling operation, even in the case of managed pressure drilling [205]. Table 4 shows the major reasons for loss of primary well control and the corresponding change in environmental variables that lead to a kick.

Insufficient mud weight and inadequate borehole-filling have high impacts on loss of well control and hydrostatic imbalance. Lost circulation has a moderate effect, and swabbing has minimal effect on the loss of well control. Moreover, a kick may occur due to some other causes e.g. sudden mud pump failure, decreasing $E C D$, and loss of control in backpressure during MPD operation. Figure 5 shows a statistical analysis of 85 kicks in deep-water drilling. Insufficient mud weight or low borehole filling causes almost $50 \%$ of kicks. Swabbing and gas cut mud is responsible for another $30 \%$ of total kicks.

\subsection{Kick warning signs}

In a regular drilling operation, mudflow into the wellbore must be equal to the mudflow out of the wellbore. Any kick in the bottomhole violates this steady-state balance of drilling mud circulation. When a kick initiated at the bottomhole, the influx towards the wellbore causes an increase in the outlet mud flow rate at the surface. Researchers defined different kick detection methods ranging from simple $[40,89,181]$ to several complex methods $[38,69,76,78]$.

A kick initiates with one or more direct or indirect warning signs. Different kick warning signs, along with their importance to kick identifications, are tabulated in Table 5. All warning signs are grouped into two categories based

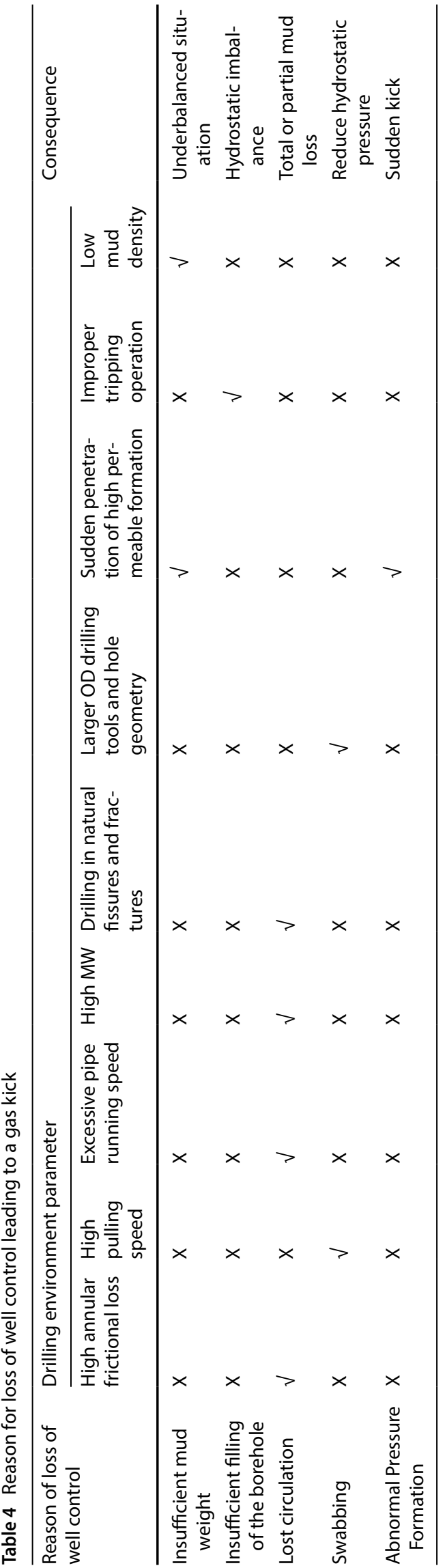

SN Applied Sciences 


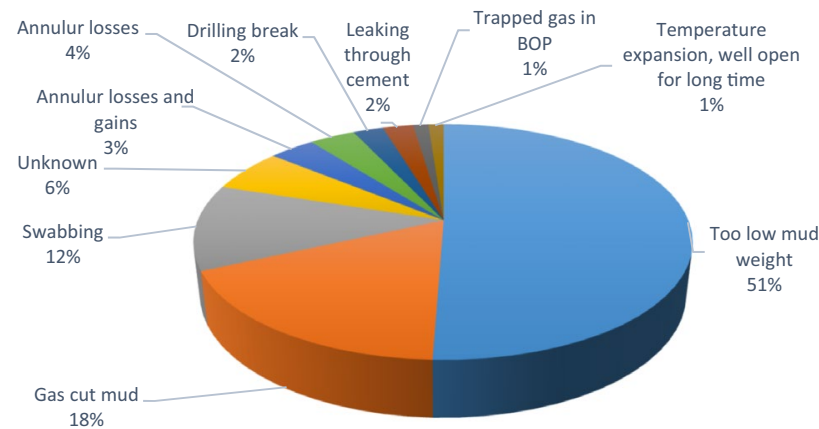

Fig. 5 Comparative study of reasons for gas kick. Data obtained from Holand and Awan [82]

on their significance level. Signs such as flow rate, increase in pit volume, flowing well with mud pump off, and inadequate borehole-filling during a trip are direct indications of an upcoming kick. These indications are termed as primary kick indicators with high significance. A high significance warning sign requires quick attention from the rig's personnel. A change in drill string weight, cut mud weight, sudden drilling break, and change in mud pump pressure are the indirect measurements of kick. These indirect measures are known as secondary kick warnings. The significance of secondary kick warning in kick indication is quite less.

\subsection{Flow measurement for kick identification}

The oil industry widely uses flow measurement as a primary kick identification tool. Most industrial flow measurement devices can measure the velocity, volumetric flow rate and mass flow rate of gas, liquid or any vapour flowing through the tubing/piping. In managed pressure drilling, a mass flowmeter, especially the "Coriolis Flowmeter," is widely used to detect the return flow rate. A continuous flow in Coriolis flowmeter is required to identify a kick. For any intermediate operation like tripping, making a connection or any interruption of fluid circulation, the Coriolis meter does not work effectively. For a mass flowmeter, Kinik [100] proposed flux calculation as

$Q_{i n}=\int_{t 1}^{t 2} q_{i n} d t$

where $q_{\text {in }}$ is defined as the mass flow meter reading at the inlet of the system and $Q_{i n}$ is the total flux during the time interval $t_{1}$ to $t_{2}$. Similarly, for outflow, [100]

$Q_{\text {out }}=\int_{t 1}^{t 2} q_{\text {out }} d t$

Then the difference in flux is calculated by employing Eqs. (2) and (3) as:

$\Delta Q=Q_{\text {in }}-Q_{\text {out }}$

The time interval is defined as $\Delta t=t_{1}-t_{2}$; usually, this time interval is $1-10 \mathrm{~min}$, based on different drilling parameters and operating conditions. Jiang et al. [92] proposed a trigger value for a kick and fluid loss at $Q_{k}=Q_{L}=80 L$ for the very deep well. So, it is assumed that a kick had occurred when $\Delta Q \geq Q_{L}$ and loss took place when $\Delta Q \leq-Q_{K}$. Fredericks et al. [59] proposed a kick detection method based on accurate return flow measurements and simultaneously measured the wellbore pressure with a special downhole arrangement.

\subsubsection{Flow measurement as early kick detection tools and kick response time}

Continuous and accurate measurement of the mass flow rate and density of the working fluid ensures drilling efficiency, predicts influx movement, and reduces the nonproductive time (NPT). A mass flowmeter can quickly detect a kick and early detection can significantly reduce kick size during detection time. Fraser et al. [58] proposed three key performance indicators for analyzing a kick.

Table 5 Standard kick indicators and their significances

\begin{tabular}{llll}
\hline Kick warning sign & Attributes & Indicator level & Significance level \\
\hline Flow rate increases & $Q_{\text {out }}>Q_{\text {in }}($ Constant $)$ & Primary & High \\
Pit volume increases & $Q_{\text {out }}>Q_{\text {in }}$ & Primary & High \\
Flowing well with mud pump off & $Q_{\text {out }}=+v e, Q_{\text {pump }}=0$ & Primary & High \\
Downhole pressure measurement (PWD) & Sudden downhole pressue change & Primary & High \\
Drilling break & Change of $R O P$ & Secondary & Medium \\
Cut mud weight & MW surface $\downarrow$ & Secondary & Low \\
Change in pump pressure & $P_{\text {pump }} \downarrow$ & Secondary & Low \\
Change in drill string weight & $W_{\text {drill_string }} \downarrow$ & Secondary & Low \\
\hline
\end{tabular}


These are: (1) Kick detection volume, (2) Kick response time, and (3) Drilling mode kick frequency. A comparison of early kick detection volume for conventional methods with and without an outflow meter, as shown in Table 6.

The drilling mode kick frequency expresses the relative frequency of kick occurrence based on different drilling operations. Fraser et al. [58] showed that $70 \%$ of kicks are likely to happen while making a connection to the drill pipe. Approximately $15 \%$ of kicks occurred during the tripping operation, while all other reasons account for another $15 \%$ of kick frequency. The use of a flowmeter can significantly reduce the influx volume by $50-70 \%$. A flowmeter plays a vital role in detecting a kick at the earliest possible time with a minor change in outflow volume. Concerning well control strategy, with a reduced influx volume, kick response time is also significantly lowered.

Fraser et al. [58] proposed three key performance indicators, but their study did not establish any correlation between kick detection volume and response time. However, kick detection volume and kick response time mostly depend on operational practice, geological nature, well trajectory, the technology used and crew skills etc. Kick response time is the sum of the time for gradual reduction of flow rate in the mud pump, a return flow check, closure of the blowout preventer (BOP) and all other related operational delays. Kinik et al. [101] investigated the consequence of total response time on all drilling variables during well control. They [101] showed that response time is the only variable that can be managed and concluded that kick size mostly depends on the total response time. Their simulation showed that the response time can be up to $10 \mathrm{~min}$ for conventional drilling with a $50 \mathrm{bbls}$ kick. Response time is much shorter in case of a closedloop MPD. It is only 4 min with 1.88 bbls kick. Their study revealed that MPD allows faster response to a kick with low influx volume.

\subsubsection{Coriolis flowmeter application in MPD and its limitations}

In an MPD system, a Coriolis flowmeter is widely used because of its high accuracy. A Coriolis flowmeter is independent of fluid properties like viscosity and density. However, the Coriolis flowmeter is expensive and has limitations regarding operating pressure, temperature and types of fluid handled. Based on the design, it can work in an environment where the temperature is as high as $350^{\circ} \mathrm{C}$ and pressure is $5000 \mathrm{psi}$ [194]. During operation, it invariably requires 3-5 psi pressure drops which indicates that it needs to be set up in a closed wellbore system like MPD. Another drawback is that a Coriolis meter does not provide an accurate result until the flow line is fully loaded or when the return mud contains gas. These limitations of the flowmeter show the need for further research and improvement of the kick detection system in MPD.

\subsection{Acoustic measurement of gas kick}

Acoustic behaviour of gas along the wellbore gives valuable information about kick propagation in the well. Bryant et al. [32] demonstrated a method of gas influx detection by observing the acoustic response of MWD tools. However, the performance of acoustic kick detection largely depends on some specific factors such as circulation rate, drilling fluid types and the tool's response frequency etc. A recent study [62] demonstrated that the drilling mud density and mud injection rate have an enormous influence on acoustic kick measurement. Different researchers described different gas kick detection methods using acoustic behaviour in the wellbore. Table 7 shows various gas kick detection methods based on acoustic measurements. Sonic methods easily detect an early gas kick; however, most of the sonic kick detection methods are based on water-based mud only. Due to significant limitations with oil-based mud, the drilling industry cannot solely rely on the acoustic measurement of a gas kick.

\subsection{Kick identification by log interpretation}

Mud logging analysis always shows precise information such as formation type, return fluid density and types of return gas. Analyzing the return fluid and cuttings gives valuable information about the formation. Al-Morakhi et al. [8] investigated micro-mud log analysis for real-time

Table 6 Early kick detection frequency versus different drilling operations

\begin{tabular}{|c|c|c|c|c|c|c|}
\hline \multicolumn{2}{|c|}{ Estimated drilling mode kick frequency (\%) } & \multirow{2}{*}{$\begin{array}{l}\text { Tripping out } \\
15 \%\end{array}$} & \multirow{2}{*}{$\begin{array}{l}\text { Making a } \\
\text { connec- } \\
\text { tion } \\
70 \%\end{array}$} & \multirow{2}{*}{$\begin{array}{l}\text { Drilling ahead } \\
5 \%\end{array}$} & \multirow{2}{*}{$\begin{array}{l}\text { Out-of-the-hole } \\
<5 \%\end{array}$} & \multirow{2}{*}{$\begin{array}{l}\text { Plug and abandon } \\
<5 \%\end{array}$} \\
\hline & & & & & & \\
\hline $\begin{array}{l}\text { Conventional drilling with- } \\
\text { out a flowmeter }\end{array}$ & $\begin{array}{l}\text { Estimated kick detection } \\
\text { volume }\end{array}$ & $\sim 3 \mathrm{bbl}$ & $>10 \mathrm{bbl}$ & $>10 \mathrm{bbl}$ & $\sim 5 \mathrm{bbl}$ & $>10 \mathrm{bbl}$ \\
\hline $\begin{array}{l}\text { Conventional drilling with a } \\
\text { flowmeter }\end{array}$ & & $\sim 1 \mathrm{bbl}$ & $\sim 5 \mathrm{bbl}$ & $\sim 3 \mathrm{bbl}$ & $\sim 5 \mathrm{bbl}$ & $\sim 5 \mathrm{bbl}$ \\
\hline
\end{tabular}


Table 7 Different acoustic kick detection methods and their limitations

\begin{tabular}{|c|c|c|c|c|c|c|}
\hline Researcher & $\begin{array}{l}\text { Bryant et al. [32], Bryant } \\
\text { and Wallace [33] }\end{array}$ & $\begin{array}{l}\text { Codazzi } \\
\text { et al. [41] }\end{array}$ & $\begin{array}{l}\text { Stokka et al. } \\
{[175]}\end{array}$ & $\begin{array}{l}\text { Bang et al. } \\
\text { [23] }\end{array}$ & Li et al. [105] & Tseytlin [190] \\
\hline Can detect early gas kick & $X$ & $\sqrt{ }$ & $\sqrt{ }$ & $\sqrt{ }$ & $\sqrt{ }$ & $\sqrt{ }$ \\
\hline Identify free gas & $\sqrt{ }$ & $\sqrt{ }$ & $\sqrt{ }$ & $\sqrt{ }$ & $x$ & $x$ \\
\hline Independent of influx location & $\mathrm{Y}$ & $x$ & $\sqrt{ }$ & $\sqrt{ }$ & $\sqrt{ }$ & $\sqrt{ }$ \\
\hline Applicable for oil-based mud & $\mathrm{X}$ & $x$ & $x$ & $x$ & $x$ & $x$ \\
\hline Can detect dissolved gas & $x$ & $x$ & $x$ & $x$ & $x$ & $x$ \\
\hline Determine presence of gas annulus & $\mathrm{x}$ & $\mathrm{x}$ & $\sqrt{ }$ & $x$ & $\sqrt{ }$ & $\sqrt{ }$ \\
\hline Identify connection gas and trip gas & $\sqrt{ }$ & $x$ & $x$ & $\sqrt{ }$ & $x$ & $x$ \\
\hline Identify influx size & $\mathrm{X}$ & $X$ & $x$ & $X$ & $X$ & $Y$ \\
\hline
\end{tabular}

$\sqrt{ }$ yes, $X$ no

drilling and early kick detection. The micro-mud sensor can work on both oil-based mud and water-based mud, and simultaneously monitor different drilling parameters every $5 \mathrm{~s}$ while monitoring the drilling progress. For the reservoir with a fracture, this log analysis can be used as a tool for early kick detection. However, for a high percentage of gas return, the micro-mud sensor produces a significant error.

Ahmed et al. [5] proposed diversification of the conventional kick detection method using real-time mud logging data for early kick detection. Monitoring the real-time mud logging data provides seven parameters for kick detection: pit gain at the surface, mudflow rate, drilling rate of penetration, total gas, pump off gas, connection gas and any drop in the pump pressure. Their proposed method can detect a small kick as well as predict any near-balance state of kick, which is going to occur. However, it is not an entirely reliable kick detection method. Additional apparatus such as an accurate flow check and trip tank must be integrated with the mud log data to understand the kick nature fully.

\subsection{Kick identification by statistical method}

The statistical method uses historical information from the nearby well, field, and geological information to predict the possibility of potential kick from a well or formation. Hargreaves et al. [76] proposed a kick detection method based on a Bayesian statistical method where an animated decision was generated based on regular noisy field data. This method shows improvement in deep-water drilling and the heaving condition. However, all statistical methods depend heavily on the accuracy of raw data. Raw data can vary with the geological location. So, a statistical method of kick identification can be used as a supporting tool for a forthcoming kick in any known formation. The major drawback of the statistical method is that it cannot be utilized for any unknown formation with confidence.
Dedenuola et al. [46] investigated historical kick volume under normal distribution to estimate the kick tolerance by a statistical model. They modelled historical data for kick volume against zero kick intensity and kick intensity against zero kick volume. This estimation also depends on formation geology, well location, well-depth, and fluid rheology.

\section{Modelling, simulation and control of MPD system}

A kick often creates a multiphase flow environment in the wellbore and annulus. For example, a gas kick always makes a two-phase flow in the annulus. The phenomena of gas bubble rise in the wellbore need to be understood first to investigate the nature of a gas kick. Below, different studies related to understanding gas kick, modelling and control are summarized.

\subsection{Factors affecting the gas bubble rise velocity in the tubing}

Most of the two-phase flow models are based on smallscale experimental results for vertical wells, inclined tubing, and annuli. These simple models do not represent actual complex wellbore geometry in real-time drilling operations [180]. Different mechanistic models characterize the annular behaviour of two-phase flow which were proposed by different researchers $[35,43,54,96,103,108$, $142,180]$. Rader et al. [148] proposed several factors that affect gas bubble rise velocity in a pipe and annulus. They identified the factors as the phase densities and viscosities of gas and liquid, fluid velocity, gas expansion rate and geometric orientation of the pipe show effect to the gas bubble rise velocity. Santos and Bourgoyne [161] proposed a two-phase flow regime with a pressure profile approximation along the wellbore. Skalle et al. [168] investigated 
the upward gas migration velocity in the annulus. Asakereh [17] investigated a flow regime analysis based on an annular acceleration parameter to detect shallow gas kick.

Table 8 summarizes several factors that affect the rise velocity of gas bubbles in the wellbore and their relative impact on bubble propagation along the annulus. Annular geometry has the highest impact on bubble propagation along a wellbore. Liquid velocity and gas expansion rates have considerable influence. In the case of mud viscosity and wellbore orientation, the effect is minimal. Apart from these four parameters, other factors have a negligible effect, as listed in Table 8.

\subsection{Mathematical model of gas kick}

An appropriate mathematical model can properly describe a kick circulation within the wellbore. Several researchers proposed different mathematical models to quantify the behaviour of gas kick in the wellbore. The following two approaches are used to simulate a gas kick: (1) Mathematical modelling, in association with the material balance equation and (2) Hands-on methodology, in-field test facilities, to study the kick behaviour under a real wellbore condition [94].

LeBlanc and Lewis [104] proposed a basic mathematical model in a controlled gas kick that used to approximate annular backpressure, equivalent mud densities and gas kick effect on casing pressure. However, gas specific gravity, influx size and gas cut drilling mud also have a detrimental effect on the casing pressure and equivalent circulating density. Mathews and McKenzie $[116,118]$ proposed different gas kick models based on pseudo-steady-state behaviour. Nickens [135] proposed a vertical well model that accounts for gas influx as a function of the formation properties and the wellbore bottom hole's operating condition. Hovland and Rommetveit [84] investigated the consequence of various constraints on gas migration velocity using a full-scale experimental setup. Many studies, both experimental and modelling $[1,56,79,102,108,147,182$, $183,196]$ focused on gas kick migration and transient behaviour, flow analysis, characteristic parameters, density distribution and annular pressure loss.

Table 9 summarizes several mathematical models for the gas kick with their applicability and limitations. Most of the gas kick models are transient models with a vertical well assumption. Very few studies [79, 147, 192, 196] described gas kick models for horizontal and deviated wells. Few models are validated through gas kick experiments in the laboratory $[79,102,104,147,192]$. Table 9 shows that most of the existing models are not capable of detecting influx. Almost all mathematical models ignored the lost circulation effect. Gas solubility in oil-based mud makes it difficult to estimate the behaviour of the gas kick along the wellbore. Few studies [147, 192] included gas solubility in the oil-based mud while propagating a transient gas kick in the wellbore. Till now, no comprehensive model is available for a gas kick to describe the complex wellbore and annulus flow behaviour.

\subsection{Control system design for kick identification}

An automated control system is a key to a successful operation in managed pressure drilling. In the MPD system, typical control variables are the flow rate of the drilling fluid, drilling fluid density, surface backpressure and downhole pressure at a specific depth. The control system always measures the return flow and compare it with an ideal condition, which enables it to find any discrepancies in a very brief period.

\subsubsection{Control objective}

In an automated MPD controller, the main objective is to monitor the pressure profile along the wellbore and maintain the desired flow rate corresponding to the system pressure. The controller also performs several
Table 8 Factors affect bubble rise velocity in wellbore

\begin{tabular}{lll}
\hline Factors & Dependency on other parameters & $\begin{array}{l}\text { Impact on } \\
\text { bubble rise } \\
\text { velocity }\end{array}$ \\
\hline Fluid density & Independent & Negligible \\
Gas void fraction & Independent & Negligible \\
Mud rheology & Independent & Negligible \\
Mud viscosity & Decreases with increasing annulus size & Small \\
Surface tension & Independent & Negligible \\
Pipe inclination & Maximum rise velocity as 45 & Small \\
Gas expansion rate & Depends on annulus backpressure & Significant \\
Annular geometry & Increase with increasing annular diameter & High \\
Liquid velocity & Increasing with flow velocity & Significant \\
\hline
\end{tabular}




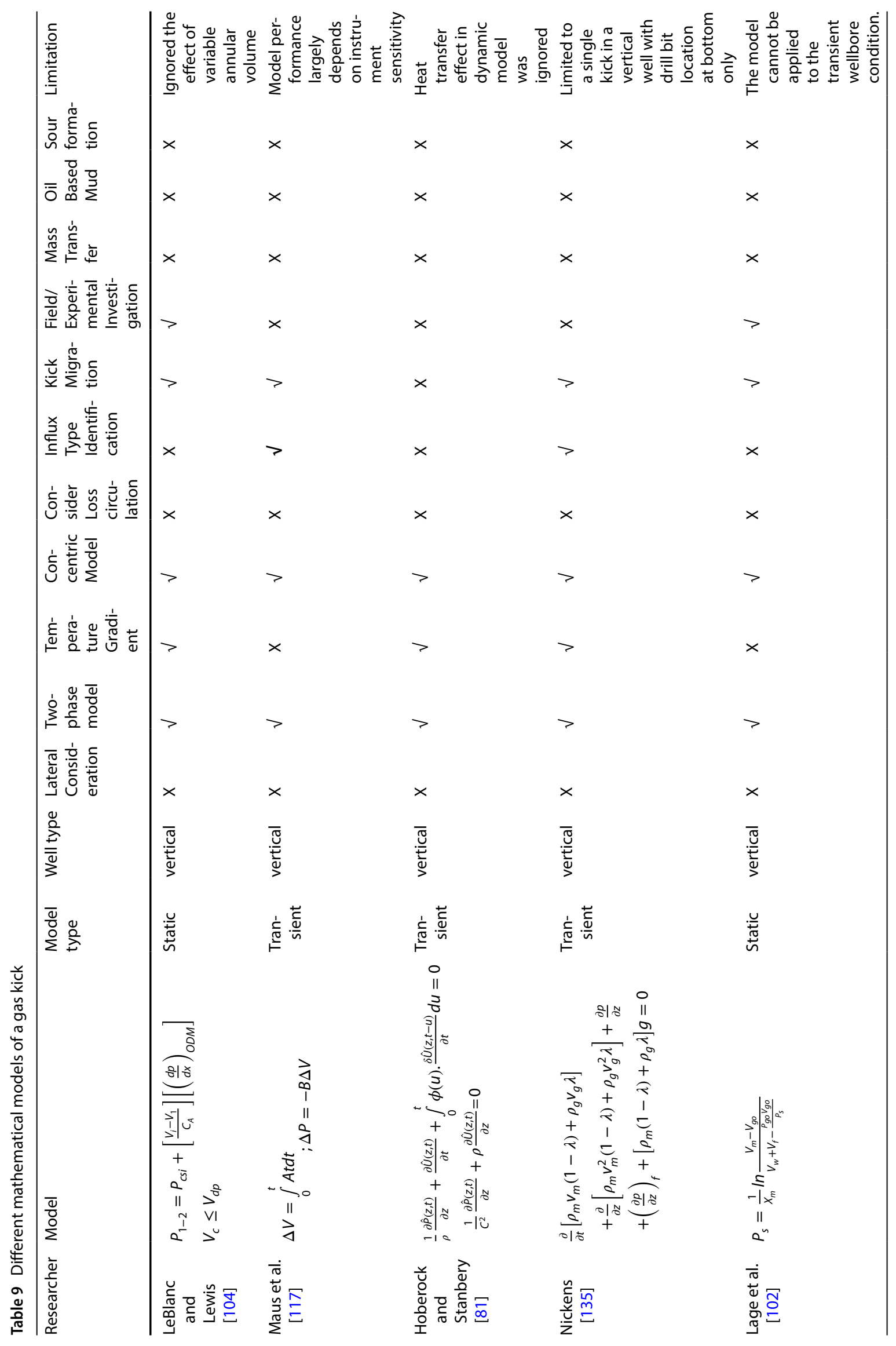




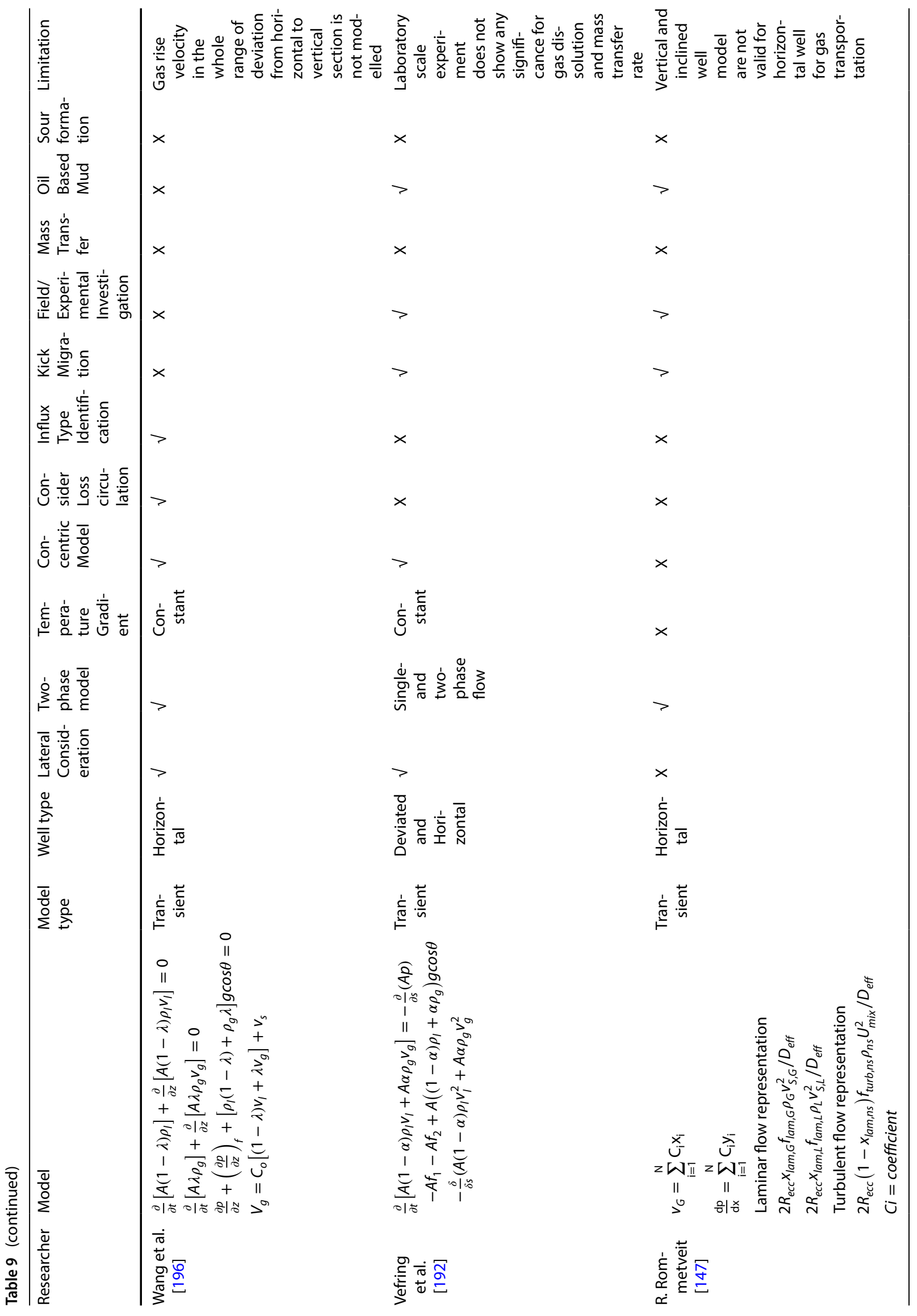




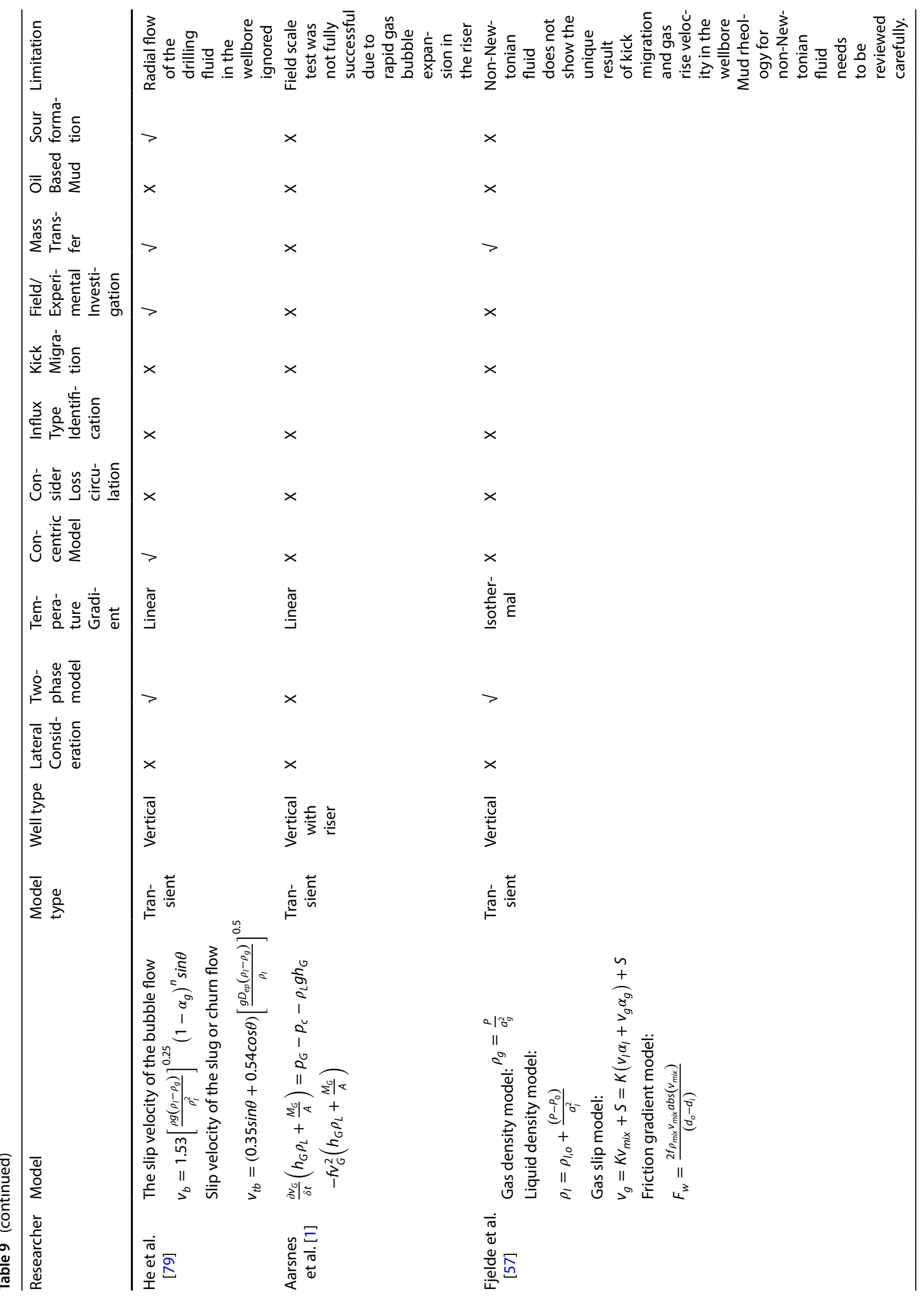


operational and failure indicators [151] for the drilling system like kick detection and lost circulation etc.

\subsubsection{Controllers in drilling automation}

With technological advancements, the drilling industry is rapidly shifting from manual drilling to automated drilling and well control systems. For an automated control system, potential controller algorithms vary based on their application, ranging from a simple proportional integral derivative (PID) controller to advanced nonlinear model predictive controllers (NMPC). The precise control of a drilling system and its response largely depend on the control system design. In the drilling application, many researchers $[66,77,128,153,166$, 213] proposed feedback controllers that can track system status like choke pressure and bottomhole pressure etc. from several physical locations of the drilling system.

A predictive controller is used to control the flow rate and choke opening based on the fluctuating flow of the return line. The NMPC controller shows better performance in field applications than the PI controller since a $\mathrm{PI}$ controller needs to be changed based on the operating condition. Several authors proposed a wide range of predictive controllers in the MPD applications. A multivariable controller showed a promising result in rejecting the disturbances and regulating BHP [31]. Eaton et al. [49] proposed three model predictive controllers with advanced switching algorithms in MPD operations. Nandan [127] proposed a robust NMPC controller that can automatically switch from pressure control mode to flow control mode in case of a gas kick while drilling.

\subsubsection{Non-linear model predictive controller design principle}

Lab-scale NMPC controllers were designed by several researchers to achieve target objectives like a pressure control and flow control in the MPD system. Mudflow rate and choke opening are the primary sources of pressure manipulation by an NMPC controller. Choke opening is controlled by the required back pressure to maintain the desired bottomhole pressure.

The NMPC utilized a nonlinear Hammerstein Weinner $(\mathrm{H}-\mathrm{W})$ model for prediction and a genetic algorithm for calculating optimal control input. Figure 6 shows a typical Hammerstein model. At the input function, with a variation of bottomhole pressure, the casing pressure is adjusted accordingly, as shown in Fig. 7. Figure 8 shows the output of the NMPC for measured pressure and NMPC simulated pressure.

\subsubsection{Kalman filter}

The reservoir management system widely used Kalman filter for many years; however, in recent days, it is also used in the drilling automation $[68,69,90,91,111]$. In designing a managed pressure drilling automation system, an appropriate design of the control system is very much essential to detect any fault during the drilling operation. A drilling fault can cause a change or deviate in the flow rate or pressure in the system from the expected value. The basic principle behind the control system is to use known input and output values to calculate or estimate the unmeasured data like system pressure, return flow rate or ever more uncertain data like dynamic frictional pressure drop in the annulus section during normal state or operation of a

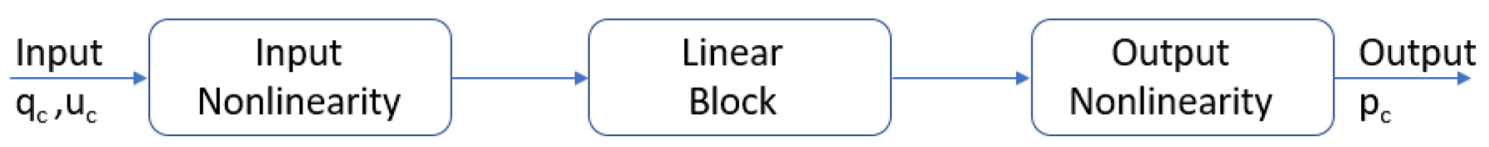

Fig. 6 Hammerstein Weiner model (Matlab 2018b)

Fig. 7 NMPC input parameter [15]

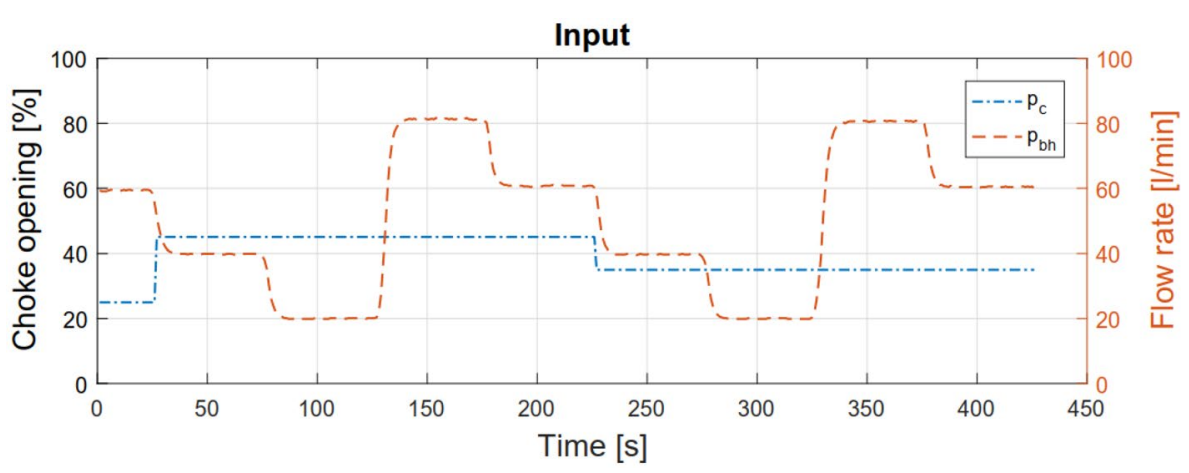

SN Applied Sciences A SPRINGER NATURE journal. 
Fig. 8 NMPC output response [15]

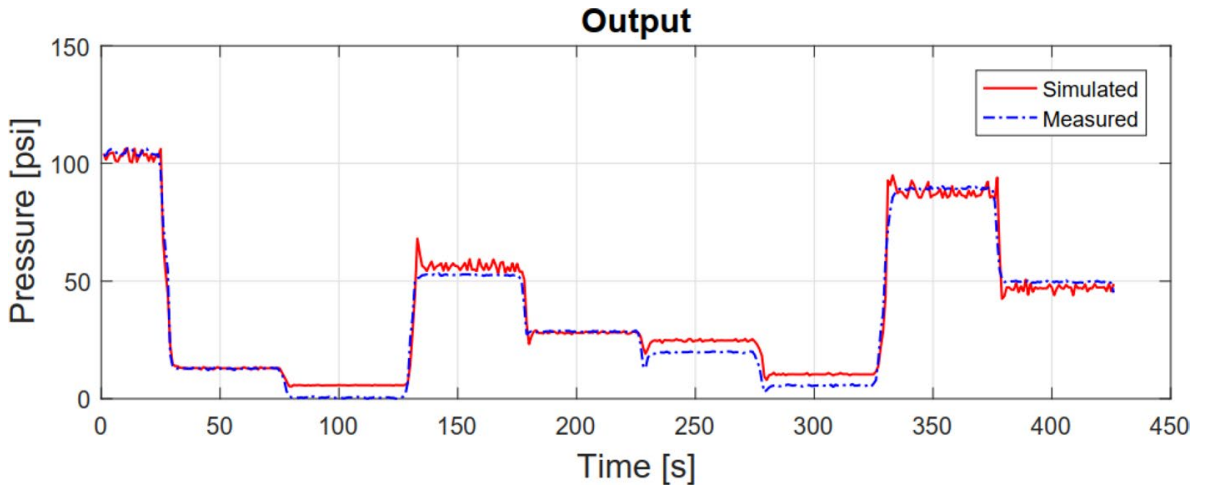

kick in the system. An unscented Kalman filter (UKF) based ensemble classifier can detect a fault in drilling operations like lost circulation or gas kick. A detailed analysis of fault nature can give an estimation of the current state of deviated behaviour in real-time.

\subsubsection{Adaptive and PID control system}

Proportional integral derivative (PID) used as an automatic feedback controller due to ease of use and implementation in the drilling system. A PID controller is widely used where there is no variation in parameters in the system since it requires proper tuning from time to time. However, during a real-time drilling operation, the system properties like drill string velocity, rotation, fluid velocity, density, rheology changes with time, which all influence the bottom hole pressure. To adapt varying changes during the drilling operation, the PID controller should be adjusted accordingly. Drilling engineer utilizes the PID controller to control the downstream choke and stabilize the downhole pressure in the system. Researchers [71, 123, 166, 172, 211, 212] proposed different approach of PID controller in drilling operation to maintain the flow rate and bottom hole pressure for kick mitigation.

\subsubsection{Control system application in MPD kick identification}

Santos et al. [160] first introduced the concept of 'MicroFlux Control' for a closed well based on fluid loss or influx detection. It instantly takes corrective measures to adjust the return flow rate and keeps the bottomhole pressure constant to regain well control. Several other studies [37, $39,48,63,72,73,119,146,152,154,163,191,193]$ proposed different control systems for MPD kick detections, equipment failure, influx management, and wellbore pressure maintenance.

Kinik et al. [100] demonstrated an automatic early kick detection method and a control mechanism to minimize kick influx by eliminating the requirement for flow check and reducing the operational delays. Bacon et al.
[20] demonstrated the advantage of the dynamic influx control techniques of MPD over the conventional drilling method. Dynamic influx control shows extensive benefits regarding well control, reduced influx size, and flexibility in kick circulation, compare to traditional methods. MPD dynamic influx control method leads to increased safety and efficiency in the overall drilling operation.

\section{Response to kick in MPD}

In conventional drilling, the initial response to a kick is well defined with standard procedures like Driller's methods, Wait and Weight method or the Bull-heading method. Kick circulation methods are selected based upon specific well condition. Gas migration location, circulation rate, mud properties, fracture gradient, and maximum allowable annular surface pressure are some of the critical factors that influence the kick circulation method. The primary well control for constant bottomhole pressure MPD is an upgrade of the Driller's method for conventional well control. The control equipment used in MPD facilities supports alternatives to the typical shutting off the well with BOP.

\subsection{Alternative response to kick in MPD}

In the drilling industry, preliminary response during a kick must be explicitly specified before recognizing a kick while drilling, so that the rig personnel can work quickly and appropriately. Response to a gas kick is very much dependent on well geometry, the relative position of a kick zone and any weak regions in the wellbore. IADC has specified a regulation and guideline for responses that should be taken for an indicated formation flow. Minerals Managements Service (MMS) has defined a well control matrix for the possible response. However, no response provides a conclusive basis for the action to be taken for a particular case like CBHP MPD [170].

Responses to a kick taken in managed pressure drilling can be grouped into two categories: circulating response 
and non-circulating response as shown in Table 10. A noncirculating response is also known as a direct shut-in or static method. The broadly acceptable non-circulating response is to shut the mud pump and close the choke in the quickest possible time. Another variation of noncirculating response is to "schedule mud pump shut down," followed by a return flow check at the surface. The latter method offers a chance to check whether the casing pressure is sufficient to stop the formation flow, or if it needs to completely shut down the well with a higher casing pressure, indicating that the kick has been taken.

Table 11 summarizes four common initial responses to kick during MPD. Once a kick is detected, an immediate shut-in of the well is the most appropriate response since this does not require any other special equipment. The modified MPD pump shutdown procedure with a choke flow check is beneficial when an uncertain kick likely to happen or a slow kick is observed. Increasing the casing pressure eliminates any pressure variations, maintains the $E C D$ and hence is a preferred method for kick response. Increasing the pump rate provides minimum casing shoe pressure and a large safety window to avoid lost return at the previous casing shoe. However, for a typical kick scenario, no single response considered as the best response. All methods are preliminary, and a single response does not apply to all situations to kick during MPD.
Table 10 Circulating response versus non-circulating response to a kick

\begin{tabular}{lll}
\hline Response type & Circulating response & $\begin{array}{l}\text { Non- } \\
\text { circulating } \\
\text { response }\end{array}$ \\
\hline Need flowmeter & & No \\
Need special equipment & Yes & No \\
Can be applied when surface equipment fails & Yes & Yes \\
Pressure at casing shoe & No & High \\
Risk of lost return for weak zone above kick zone & Low & High \\
Response time & Low & Delayed \\
Kick size & Short & Larger \\
Pressure fluctuation at bottomhole & Smaller & High \\
Choke pressure and casing shoe pressure variation & Low & High \\
Pit gain at surface & Low & High \\
Response varies with well geometry & Low & No \\
\hline
\end{tabular}

Table 11 Comparison of initial response to a kick in MPD

\begin{tabular}{|c|c|c|c|c|}
\hline Response & Shut in & $\begin{array}{l}\text { Modified MPD pump } \\
\text { shutdown }\end{array}$ & $\begin{array}{l}\text { Rapid increasing the cas- } \\
\text { ing pressure }\end{array}$ & $\begin{array}{l}\text { Stepwise increas- } \\
\text { ing the pump } \\
\text { rate }\end{array}$ \\
\hline Response type & Non circulating & Non circulating & Circulating & Circulating \\
\hline Flow check & $X$ & $\sqrt{ }$ & $\sqrt{ }$ & $\sqrt{ }$ \\
\hline Check for low rate kick & $X$ & $\sqrt{ }$ & $\mathrm{x}$ & $X$ \\
\hline Need for special equipment & $X$ & $X$ & $\sqrt{ }$ & $\sqrt{ }$ \\
\hline Minimum risk of lost circulation & $\sqrt{ }$ & $\mathrm{X}$ & $\sqrt{ }$ & $\sqrt{ }$ \\
\hline Well defined procedure & $\sqrt{ }$ & $x$ & $\mathrm{x}$ & $\mathrm{x}$ \\
\hline Minimize casing shoe pressure & $x$ & $x$ & $x$ & $\sqrt{ }$ \\
\hline Applicable for large hole size & $\sqrt{ }$ & $\sqrt{ }$ & $\sqrt{ }$ & $x$ \\
\hline Requires accurate flow metering & $x$ & $x$ & $\sqrt{ }$ & $\sqrt{ }$ \\
\hline Executed by surface BOP & $\sqrt{ }$ & $\mathrm{X}$ & $\mathrm{X}$ & $\mathrm{X}$ \\
\hline Detect lost return & $X$ & $X$ & $\sqrt{ }$ & $X$ \\
\hline Wide safety margin & $X$ & $x$ & $\sqrt{ }$ & $\sqrt{ }$ \\
\hline Quick kick detection & $\mathrm{X}$ & $\mathrm{X}$ & $\sqrt{ }$ & $x$ \\
\hline Maintain underbalanced condition & $\mathrm{x}$ & $\sqrt{ }$ & $\mathrm{x}$ & $x$ \\
\hline Pressure fluctuation at bottomhole & $\sqrt{ }$ & $x$ & $x$ & $x$ \\
\hline
\end{tabular}

$\sqrt{ }$ yes, $X$ no 


\subsubsection{Kick response to compressible flow}

For general kick response, the preliminary assumption is based on a "flow continuity". It indicates that there is no influx for incompressible fluid flow. Flow continuity is not truly applicable to any compressible fluid flow in the wellbore. For a compressible flow, obtaining $\mathrm{Q}_{\text {out }}=\mathrm{Q}_{\text {in }}$ does not prove an influx stops. Bacon et al. [22] investigated the transient kick response to multiphase compressible flow behaviour in the wellbore with a control volume approach. They proposed a dynamic response by applying a backpressure method to obtain the $Q_{\text {out }}=Q_{\text {in }}$ and maintain this condition until the influx stops. During a gas kick, influx cessation may occur when $Q_{\text {expansion }}=0$ within the well after maintaining $Q_{\text {out }}=Q_{\text {in }}$.

This influx cessation may take an arbitrary period. Bacon et al. [22] studies could not approximate the time to stop the influx of compressible flow. This methodology needs to be investigated thoroughly for different mud rheology, reservoir fluid composition, operating pressure, and temperature.

\subsection{MPD kick response decision tree}

A decision tree expresses simplified decision-making criteria during drilling for several alternative solutions based on the available equipment and resources. Davoudi et al. [45] designed a basic decision-making response algorithm for MPD, as shown in Fig. 9.

This decision tree is based on the currently available flowmeters and other industrial equipment. Accurate flow detection is the key concern of this decision tree. Based on a positive flow check, Davoudi proposed an MPD mud pump shutdown schedule, increasing casing pressure and completely shutting down the well to mitigate the influx. Different researchers $[45,95,171]$ proposed several alternative responses to kick other than a conventional shutdown, with different algorithms. They proposed decision trees and algorithms to select the initial response to kick from a set of alternatives. These decision trees can be used during the planning phase of a drilling program, which is based on the well configuration, available equipment, desired kick tolerance and decisions about the kick warning signal. The goal of their work is to select the best response during the planning phase that would give the maximum kick tolerance with available resources, well geometry and a given operating condition. Table 12 shows a comparison of different kick response scenarios. Based on the comparison, it is evident that no single proposal seems widely applicable as a comprehensive response to kick.

\subsection{Risk evaluation}

An appropriate risk analysis is adopted as a mitigation tool for any unwanted situation during a drilling operation. Risk analysis is a crucial tool to develop strategies to prevent accidents and develop an appropriate mitigation plan. Risk analysis serves in two ways. It determines the acceptable risk and identifies the major contributing risk factor. Once the risk factors identified, a preventive measure can be evaluated for each risk factor. Table 13 shows the category of a blowout and its consequence.

Different risk analysis method in the drilling operation such as Bow- tie approach, Bayesian network are available in the literature. Bow Tie Approach [88, 97, 98, 169] enable the breakdown of entire systems from root cause to the final consequences. A general bow-tie model considers basics events, intermediate events, top events, safety barriers and consequences. A graphical bow-tie model is helpful for the visualization of risk assessment. Though the bow-tie model is simple to use; however, the application of this failure analysis is limited to complex system due to common cause of failure and conditional dependencies on other events.

Bayesian network (BN) $[3,97,99,134,177]$ is also used as a prominent drilling risk analysis tool in recent years. A Bayesian network begins with node, arcs, and
Fig. 9 Simplified algorithm of MPD kick response. Redrawn from Davoudi et al. [45]

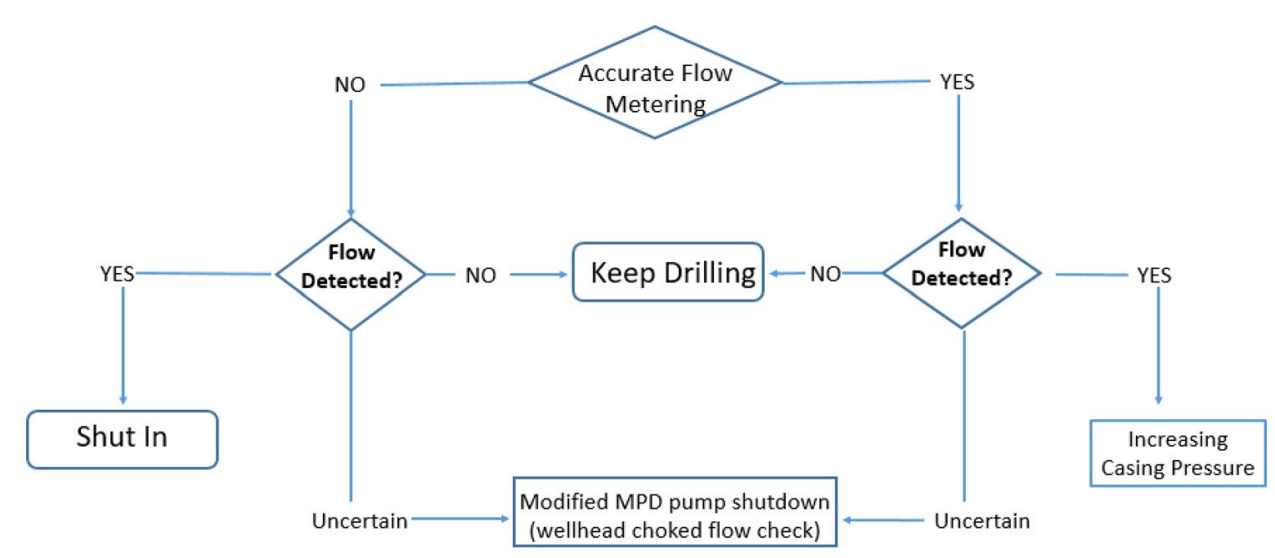


Table 12 Alternative response to kick proposed by different authors

\begin{tabular}{|c|c|c|c|}
\hline Researcher & Davoudi et al. [45] & Smith and Patel [171] & $\begin{array}{l}\text { Karimi } \\
\text { Vajargah } \\
\text { and van } \\
\text { Oort [95] }\end{array}$ \\
\hline Response type & $\begin{array}{l}\text { Circulating and non-circu- } \\
\text { lating }\end{array}$ & Circulating & $\begin{array}{l}\text { Circulating } \\
\text { and non- } \\
\text { circulating }\end{array}$ \\
\hline Increasing/modify mud pump rate & $\sqrt{ }$ & $\sqrt{ }$ & $\sqrt{ }$ \\
\hline Increase annular backpressure & $\sqrt{ }$ & $\mathrm{X}$ & $\sqrt{ }$ \\
\hline Conventional shutdown & $\sqrt{ }$ & $x$ & $\sqrt{ }$ \\
\hline Evaluate change in mud weight & $\mathrm{x}$ & $\sqrt{ }$ & $x$ \\
\hline Evaluate casing pressure & $x$ & $\sqrt{ }$ & $\sqrt{ }$ \\
\hline Response to increase in casing pressure & $x$ & $\sqrt{ }$ & $\sqrt{ }$ \\
\hline Response beyond kick tolerance limit & $\sqrt{ }$ & $x$ & $x$ \\
\hline Depends on flowmeter accuracy & $x$ & $\sqrt{ }$ & $\sqrt{ }$ \\
\hline Response to kick due to lost circulation & $x$ & $\mathrm{X}$ & $\sqrt{ }$ \\
\hline Algorithm for early kick detection & $\mathrm{X}$ & $x$ & $\sqrt{ }$ \\
\hline Monitor flow, pump pressure, pit gain, fluid loss etc. & $x$ & $x$ & $\sqrt{ }$ \\
\hline Response depends on other drilling uncertainties & $\sqrt{ }$ & $\mathrm{X}$ & $\sqrt{ }$ \\
\hline
\end{tabular}

$\sqrt{ }$ yes, $X$ no

Table 13 Category of blowout consequences [88]

\begin{tabular}{lll}
\hline Index & Consequences & Description \\
\hline 1 & Near Miss & Event that does not result in actual loss but has potential to do so \\
2 & Mishap & Event that causes minor health effects and/or minor effects to property and environment \\
3 & Incident & Event that can cause considerable harm or loss \\
4 & Accident & Event that may cause one or more fatalities or permanent major disabilities \\
5 & Disaster & Event that can cause multiple fatalities and extensive damage to the property, system, \\
& and production \\
\hline
\end{tabular}

corresponding probability functions to produce a set of random variables and provisional dependencies among them.

\subsection{MPD decision matrix for well control}

A well control matrix can perform as a substitute of the decision tree. A well control matrix helps the drilling crew to take an instant decision to continue drilling within a safe operating window. It allows a well control system to switch from dynamic well control to conventional well control methods when required. The IADC MPD [121] subcommittee also proposed a Well Control Matrix (WCM) as a guideline for CBHP MPD well control.

Well control matrix explains the proper action to maintain the primary barrier of the system, influx management and enable the transfer to the secondary barrier, such as well control, when necessary. Table 14 shows a sample well control matrix. Several studies [21, 42, 83, 149, 163, 184, 194] also proposed a variety of simplified well control matrices to control the flow, influx management, and provide a guideline for well control within safe operational limits.

\subsubsection{Kill method}

Several studies $[83,122,149]$ proposed MPD operation and kill methods based on the influx gain ranging from 0 to 10 bbl. Different operating envelopes at different hole sections were proposed for different levels of pit gain with a variety of conditions like drilling, pump off, connection etc. A proper selection of mud weight and mud pump rate are critical during a killing method. 
Table 14 Sample MPD operation matrix [121]

\begin{tabular}{|c|c|c|c|c|c|}
\hline \multirow{2}{*}{\multicolumn{2}{|c|}{$\begin{array}{l}\text { MPD Drilling } \\
\text { Matrix }\end{array}$}} & \multicolumn{4}{|c|}{ Surface Pressure Indicator } \\
\hline & & \multirow{2}{*}{$\begin{array}{l}\text { At Planned Drilling } \\
\text { Back Pressure } \\
\text { Continue Drilling }\end{array}$} & \multirow{2}{*}{$\begin{array}{c}\text { At Planned } \\
\text { Connection Back } \\
\text { Pressure }\end{array}$} & \multirow{2}{*}{$\begin{array}{c}>\text { Planned Back Pressure } \\
\text { \& < Back Pressure Limit } \\
\text { Increase pump rate, mud } \\
\text { weight, or both AND reduce } \\
\text { surface pressure to planned } \\
\text { or contingency levels. }\end{array}$} & \multirow{2}{*}{$\begin{array}{c}\geq \text { Back } \\
\text { Pressure Limit } \\
\begin{array}{c}\text { Pick up, shut in, } \\
\text { evaluate next } \\
\text { action }\end{array}\end{array}$} \\
\hline \multirow{4}{*}{ 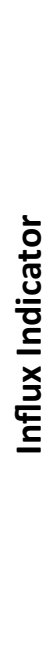 } & No Influx & & & & \\
\hline & $\begin{array}{c}\text { Operating } \\
\text { Limit }\end{array}$ & $\begin{array}{l}\text { Increase } \\
\text { pressure, pump rate, } \\
\text { mud weight, or a } \\
\text { combination of all }\end{array}$ & $\begin{array}{l}\text { Increase } \\
\text { pressure, pump rate, } \\
\text { mud weight or a } \\
\text { combination of all }\end{array}$ & $\begin{array}{l}\text { Increase pump rate, mud } \\
\text { weight or both AND reduce } \\
\text { surface pressure to plan of } \\
\text { contingency levels. }\end{array}$ & $\begin{array}{c}\text { Pick up, shut in, } \\
\text { evaluate next } \\
\text { action }\end{array}$ \\
\hline & $\begin{array}{c}<\text { Planned } \\
\text { Limit }\end{array}$ & $\begin{array}{l}\text { Cease Drilling, } \\
\text { Increase back } \\
\text { pressure, pump rate, } \\
\text { mud weight or a } \\
\text { combination of all }\end{array}$ & $\begin{array}{l}\text { Cease Drilling. Increase } \\
\text { back pressure, pump } \\
\text { rate, mud weight or a } \\
\text { combination of all }\end{array}$ & $\begin{array}{c}\text { Pick up, shut in, evaluate } \\
\text { next action }\end{array}$ & $\begin{array}{c}\text { Pick up, shut in, } \\
\text { evaluate next } \\
\text { action }\end{array}$ \\
\hline & $\begin{array}{l}\geq \text { Planned } \\
\quad \text { Limit }\end{array}$ & $\begin{array}{l}\text { Pick up, shut in, } \\
\text { evaluate next action }\end{array}$ & $\begin{array}{l}\text { Pick up, shut in, } \\
\text { evaluate next action }\end{array}$ & $\begin{array}{c}\text { Pick up, shut in, evaluate } \\
\text { next action }\end{array}$ & $\begin{array}{c}\text { Pick up, shut in, } \\
\text { evaluate next } \\
\text { action }\end{array}$ \\
\hline
\end{tabular}

\section{Recent advancement and scope of future work on MPD}

Though the oil industry has adopted MPD for a decade, still there are some scopes for further improvement in MPD. The following section discusses some scopes of work for MPD advancement.

\subsection{Application of machine learning}

Machine learning, a subclass of Artificial Intelligence (AI) is a popular tool in well control and kick management systems. Machine learning uses a different mathematical model on a sample data point or "training data," the model about the system and its response. Once the training points are established, they can be used to make a prediction and decision-making tool. In recent years, the oil industry widely used machine learning and data-driven solution like fuzzy logic, support vector machine and artificial neural network [13].

In a drilling system, inputs are mud weight, fluid viscosity, drill pipe rotation, weight on bit, rate of penetration, and ECD; whereas the output can be cuttings return rate, return mud flow rate, return gas volume fraction etc. Once the ANN model developed for a given data set, it can be utilized to generate output for an unknown input. ANN used in the different aspects of a drilling operation. In recent years, ANN used in drill bit selection [16, 25, 64,
114], dynamic behaviour of non-linear drilling system [44], troubleshooting $[6,107,141]$, wellbore instability [139], ROP estimation [124], lost circulation [12], fluid rheology, hydraulics $[2,7,51,60,195]$ and managed pressure drilling operation $[9,10,150,207,209]$.

\subsubsection{Measured data quality}

Each system in a drilling operation like hook load, rotary speed, flow rate, standpipe pressure, mud pit volume etc. generate a vast amount of real-time drilling data. However, Ashok et al. [18] studies show doubt about the collected drilling data. The deviation of measured data from their accepted values must be estimated to ensure useful representative data. Automated data validation tools can be used to achieve this. Another corrective measure can be taken once a source error is detected. Artificial Intelligence (Al) and machine learning tools like Artificial Neural Network (ANN) [137, 187], data clustering [138] can be applied to rectify the large volume of data and any outlier involved in the collected data. Raw drilling data should be filtered, cleaned and combined with available drilling performance equations to measure the drilling performance [173].

\subsection{Wellbore geometry}

The impact of wellbore geometry $[120,178]$ is crucial to model a gas kick and kick response during the MPD operation. Rostami et al. [155] and Tian et al. [186] studied 
parametric analysis of MPD hydraulics. They have shown that the wellbore geometry, hole size and drill string arrangement have an impact on hydrodynamic friction and hydrostatic pressure loss calculation. For a slanted or deviated well, a proper simulation study can predict the kick warning, considering appropriate MPD hydraulics.

\subsection{MPD in HPHT well}

High pressure and high temperature (HPHT) can affect mud rheology and properties actively and hence impact the well control as well $[19,24,52,65,174,206]$. Excellent thermal stability of drilling mud is required [203] for an HTHP well. Past studies show that oil-based drilling mud provides an excellent solution to thermal stability compared to the water-based drilling mud for an HTHP well $[162,204]$. Oil-based drilling fluid is widely used for HPHT well $[27,36,157]$ though gas kick detection with oil-based mud is more difficult to detect. The multiphase flow behaviour for a water-based mud shows a significant difference compared to an oil-based mud. The gas solubility in an oil-based mud is increased with an increase in pressure. The gas influx from the formation dissolved into the oil-based mud as solution gas, which indicates a low pit gain on the surface. This gas suddenly expands near the surface when wellbore pressure drops significantly may lead to an uncontrolled blow out situation. Predicting the temperature and pressure distribution along the wellbore is more complicated while drilling in an HPHT well with oil-based mud.

Several studies [27, 55, 87, 188, 201] proposed models for the prediction of pressure and temperature modelling in HPHT well. A temperature modelling should include the rheological, thermophysical properties of drilling mud. In addition to a wide range of physical properties of influx fluid, e.g. pressure, temperature, and specific gravity can be considered. The typical measurement of downhole pressure needs to be adjusted for HPHT well due to fluid expansion and compression for high pressure and temperature.

\subsubsection{Solubility of gas in OBM, SBM}

During gas kick modelling, one of the critical assumptions is that gas enters from the formation into the wellbore as a single bubble and remains the same along the wellbore. The solubility of this gas or bubble in synthetic-based mud (SBM) and oil-based mud (OBM) [112] is often ignored in gas rise velocity calculation for the simplification purpose. Nickens [135] showed that the pressure calculation of a single bubble is always higher than anticipated. In nonaqueous drilling mud like SBM or OBM, the solubility of the gas in drilling mud is not uniform. So, the gas solubility is a significant concern and cannot be ignored [110]. Therefore, proper kick detection time and pit volume may vary based on mud characteristics. Most of the recent studies on MPD are based on water-based mud and ignore the solubility of a gas in the drilling fluid. Karimi Vajargah and van Oort [95] only described a simple correlation of pit gain in SBM. For a rigorous MPD gas kick model, the solubility of the gas bubble in oil-based mud needs to explore.

\subsection{Transient pressure response}

Bacon et al. [22] introduced a dimensionless, transient parameter known as the 'Pressure Transfer Parameter' (PTP), which provides the BHP response on the WHP in a dynamic well control system. This PTP can significantly improve current MPD operations and well control systems regarding influx sizes and reduce surface backpressure. This parameter can be a good kick indicator for the compressible influx. Therefore, a comprehensive early kick detection model can be developed by incorporating PTP in MPD operation.

\subsection{Pipe rotation and buckling}

Pipe eccentricity and rotation influence fluid transition from laminar to turbulent flow. These also influence annular pressure calculation. Erge et al. [53] presented a mathematical model to incorporate these effects in calculating the bottomhole pressure during MPD. The effect of drill pipe rotation and drill pipe buckling, and eccentricity need to be investigated thoroughly to evaluate the kick in MPD.

\subsection{Computational fluid dynamics (CFD) of annular profile}

Computational fluid dynamics (CFD) [143] and numerical modelling [109] of annular pressure profile and wellbore geometry can provide insight into the annular behaviour of MPD. CFD can be used to simulate the kicking behaviour, influx distribution, annular pressure loss, and fluid rheology. CFD analysis can also deal with pipe eccentricity and the pipe rotation effect during drilling. Illustration of lost return in the fracture by CFD can demonstrate the behaviour of a gas kick during lost circulation.

\subsection{Sour formation}

Offshore carbonate formation at an HPHT $[34,67]$ zone is defined as sour gas reservoir, which also has a narrow drilling window. Any fracture in the sour gas formation causes the gas to invade the well easily and stimulate dangerous 
gas kicks $[34,156]$. Conventional managed pressure drilling cannot fully satisfy the operating condition in highpressure sour formations. Also, lost circulation may cause a kick in the sour formation. Traditional methods cannot be applied for controlling the bottomhole pressure in this type of formation. In this case, an alternative is necessary to estimate the bottomhole pressure.

\subsection{Mud logging}

Real-time mud logging gives valuable information about the formation and a blowout. A kick can be estimated from continuous log analysis for return mud and fluid composition $[5,8,28,47]$. Logging data identifies a change in the behaviour of formation before a kick happens. Utilization of real-time mud logging data with a gas kick model helps to improve the available kick response behaviour.

\subsection{Gas hydrate effect}

Drilling in unconventional formation like gas hydrate brings up new challenges to the drilling industry. Gas hydrates are known as solid crystalline substances where a large amount of methane is trapped within the crystalline structure of the water, forming ice or ice-like substance. Drilling in a gas hydrate formation generates cuttings with gas hydrates. Decomposing gas hydrates from cuttings can produce a large amount of gas in the annulus section due to a change in temperature and pressure as proceed to the wellhead, which might cause a gas kick [61, 199].

Any kick from the gas hydrate formation may comprise of a mixture of solid, gas and liquid flow [106, 197]. Hydrates dissociation during drilling operations can cause wellbore instability. Also, there might be hydrate formation in the BOP, wellhead and choke like while circulating a gas kick from the wellbore [125]. Many researchers [61, $106,179,197,199]$ investigated the gas kick behaviour for a hydrate formation considering a multiphase flow behaviour. However, in-depth research on gas hydrate kick modelling still needs attention from the researcher.

\section{Conclusion}

Conventional overbalanced drilling is not always feasible when drilling in critical reservoir conditions and narrow drilling windows. Managed pressure drilling offers a technical solution to the petroleum industry to explore complex geological formation. Early kick detection plays a vital role in offshore MPD, where kick volume tolerance is crucial. In this manuscript, environmental variables for gas kick and different kick detection methods discussed systematically. However, considerable uncertainty is involved in kick warning sign in terms of reservoir type, geological nature, drilling depth and orientation. This study summarized different early kick detection warning signs with their significance level. In any drilling operation, the response to kick should be appropriately stated based on the kick intensity and propagation rate along the wellbore. Different responses to kick and kick mitigation algorithms for MPD are systemically analyzed in this study. Several alternative responses to kick during MPD are available, but each response to kick has its limitations. Four responses (i.e. shut-in well, modified pump shutdown method, increasing casing pressure, and increasing the pump rate) are to be more efficient than others. Researchers proposed different decision- making trees for kick response; however, a single decision-making criterion for kick response cannot be applied in all drilling environments. Therefore, this work suggests further improvement in managing kick response behaviour. Finally, this work summarizes recent progress and scope for further studies in the drilling methods. Future research should focus on the recent progress of advanced machine learning methods, and geologically challenging HPHT well and hydrate reservoir. A CFD study can be used to simulate gas kick behaviour in the wellbore at the different drilling conditions.

Acknowledgements The authors would like to thank the Research and Development Corporation of Newfoundland and Labrador (RDC), Funding No. 210992 and Statoil Canada Ltd., Funding No. 211162, for providing financial support to accomplish this research under the Statoil Chair in Reservoir Engineering at Memorial University of Newfoundland, St. John's, NL, Canada. This publication was also made possible by the grant of QU-IRCC and Texas A\&M University at Qatar.

\section{Compliance with ethical standards}

Conflict of interest The authors declare that they have no conflict of interest.

\section{References}

1. Aarsnes UJF, Hauge E, Godhavn JM (2016) Mathematical modeling of gas in riser. In: SPE deepwater drilling and completions conference, Texas, USA. https://doi.org/10.2118/180292-ms

2. Abdelgawad K, Elkatatny S, Moussa T, Mahmoud M, Patil S (2019) Real-time determination of rheological properties of spud drilling fluids using a hybrid artificial intelligence technique. J Energy Resour Technol Trans ASME. https://doi. org/10.1115/1.4042233

3. Abimbola M, Khan F (2016) Development of an integrated tool for risk analysis of drilling operations. Process Saf Environ Prot 102:421-430. https://doi.org/10.1016/j.psep.2016.04.012

4. Agustinus K, Zein JM, Irawan F, Wuest C (2016) Managed pressure drilling application to deploy lower completion safely and efficiently in static-underbalanced well. In: Offshore technology 
conference Asia, Kuala Lumpur, Malaysia, 22-25 March 2016. https://doi.org/10.4043/26713-ms

5. Ahmed MA, Hegab OA, Sabry A (2015) Early detection enhancement of the kick and near-balance drilling using mud logging warning sign. Egypt J Basic Appl Sci 3:85-93. https://doi. org/10.1016/j.ejbas.2015.09.006

6. Al-AbdulJabbar A, Elkatatny S, Mahmoud M, Abdulraheem A (2018) Predicting rate of penetration using artificial intelligence techniques. In: SPE Kingdom of Saudi Arabia annual technical symposium and exhibition, Dammam, Saudi Arabia. https://doi.org/10.2118/192343-ms

7. Al-Azani K, Elkatatny S, Abdulraheem A, Mahmoud M, AlShehri D (2018) Real time prediction of the rheological properties of oil-based drilling fluids using artificial neural networks. In: SPE Kingdom of Saudi Arabia annual technical symposium and exhibition 2018, Dammam, Saudi Arabia. https://doi.org/10.2118/192199-ms

8. Al-Morakhi R, Al-Shemali A, Alsammak I, Esterabadi J, Martocchia A, Ferroni G, Marai N, Shoeibi A, Janbakhsh M (2013) Real time advanced flow analysis for early kick/loss detection \& identification of open fractures. In: Kuwait oil and gas show and conference, Mishref, Kuwait. https://doi. org/10.2118/167335-ms

9. Al-Yami AS, Al-Shaarawi A, Al-Bahrani H, Wagle VB, AlGharbi S, Al-Khudiri MB (2016) Using Bayesian network to develop drilling expert systems. In: SPE heavy oil conference and exhibition 2016, Kuwait City, Kuwait. https://doi. org/10.2118/184168-ms

10. Al-Yami AS, Schubert J (2012) The use of artificial Bayesian intelligence in practical well control. In: SPE Russian oil and gas exploration and production technical conference and exhibition, Moscow, Russia. https://doi.org/10.2118/160662-ru

11. Alkamil EHK, Abbood HR (2018) Using managed pressure drilling to reduce stuck pipe problem. In: SPE Kingdom of Saudi Arabia annual technical symposium and exhibition, Dammam, Saudi Arabia, 23-26 April 2018

12. Alkinani HH, Al-Hameedi ATT, Dunn-Norman S, Alkhamis MM, Mutar RA (2019) Prediction of lost circulation prior to drilling for induced fractures formations using artificial neural networks. In: SPE Oklahoma city oil and gas symposium, Oklahoma City, Oklahoma, USA. https://doi.org/10.2118/195197-ms

13. Alkinani HH, Al-Hameedi ATT, Dunn-Norman S, Lian D (2019) Application of artificial neural networks in the drilling processes: can equivalent circulation density be estimated prior to drilling? Egypt J Pet. https://doi.org/10.1016/j.ejpe.2019.12.003

14. Almetayev R, Al Hosani M, Al Ameri S, Al Mutawa A, Hussain MA (2018) First nitrified managed pressure drilling application in United Arab Emirates. In: Abu Dhabi international petroleum exhibition \& conference, Abu Dhabi, UAE, 12-15 November 2018

15. Amin A (2017) Modeling and control of managed pressure drilling operations. Memorial University of Newfoundland

16. Arehart RA (1989) Drill bit diagnosis using neural networks. In: Society of petroleum engineers, AIME, SPE DELTA, pp 24-28

17. Asakereh $R$ (2011) Flow regime analysis assists early detection of a shallow gas kick. In: SPE Middle East oil and gas show and conference, Manama, Bahrain. https://doi.org/10.2118/140841-ms

18. Ashok $P$, Ambrus $A$, Ramos $D$, Lutteringer J, Behounek $M$, Yang YL, Thetford T, Weaver T (2016) A step by step approach to improving data quality in drilling operations: field trials in North America. In: SPE intelligent energy international conference and exhibition, Aberdeen, United Kingdom. https://doi. org/10.2118/181076-ms

19. Avelar CS, Ribeiro PR, Sepehrnoori K (2009) Deepwater gas kick simulation. J Pet Sci Eng 67:13-22. https://doi.org/10.1016/j. petrol.2009.03.001
20. Bacon W, Sugden C, Brand P, Gabaldon O, Culen M (2016) MPD dynamic influx control mitigates conventional well control pitfalls. In: SPE/IADC managed pressure drilling and underbalanced operations conference and exhibition, Galveston, Texas, USA. https://doi.org/10.2118/179185-ms

21. Bacon W, Sugden C, Gabaldon O (2015) From influx management to well control; revisiting the MPD operations matrix. In: SPE/IADC drilling conference, London, United Kingdom. https ://doi.org/10.2118/173174-ms

22. Bacon W, Tong A, Gabaldon O, Sugden C, Suryanarayana PV (2012) An improved dynamic well control response to a gas influx in managed pressure drilling operations. In: SPE/IADC drilling conference, San Diego, California, USA. https://doi. org/10.2118/151392-ms

23. Bang J, Mjaaland S, Jensen LK, Hendriks P (1994) Acoustic gaskick detection with wellhead sonar. In: SPE annual technical conference and exhibition, New Orleans, LA, USA. https://doi. org/10.2118/28317-ms

24. Bassam A, Del Castillo AÁ, García-Valladares O, Santoyo E (2015) Determination of pressure drops in flowing geothermal wells by using artificial neural networks and wellbore simulation tools. Appl Therm Eng 75:1217-1228. https://doi.org/10.1016/j. applthermaleng.2014.05.048

25. Bilgesu HI, Al-Rashidi AF, Aminian K, Ameri S (2001) An unconventional approach for drill-bit selection. In: SPE Middle East oil show, Bahrain. https://doi.org/10.2523/68089-ms

26. Bjørkevoll KS, Molde DO, Rommetveit R, Syltøy S (2008) MPD operation solved drilling challenges in a severely depleted $\mathrm{HP} / \mathrm{HT}$ reservoir. In: SPE/IADC drilling conference, Orlando, Florida, USA, 4-6 March 2008, pp 1154-1165. https://doi. org/10.2118/112739-ms

27. Bland, R., Mullen, G., Gonzalez, Y., Harvey, F., Pless, M., Hughes, B., 2006. HP/HT Drilling Fluid Challenges, in: IADC/SPE Asia Pacific Drilling Technology Conference and Exhibition. Bangkok, Thailand

28. Blue, D., Blakey, T., Rowe, M., 2019. Advanced mud logging: Key to safe and efficient well delivery, in: Annual Offshore Technology Conference. Houston, Texas, USA, 6 - 9 May 2019, pp. 6-9. https://doi.org/10.4043/29469-ms

29. Borges S, Dobrokhleb P, Krivolapov D, Magda A, Soroka T, Moiseenko I (2018) Successful application of different managed pressure drilling techniques in Russia: identification of challenges and selection of the optimum approach. In: SPE annual Caspian technical conference and exhibition, Astana, Kazakhstan, 31st October-2nd November 2018. https://doi. org/10.2118/192533-MS

30. Brakel JD, Tarr BA, Cox W, Jørgensen F, Straume HV (2015) SMART kick detection; first step on the well control automation journey. In: SPE/IADC drilling conference, proceedings, pp 725-741

31. Breyholtz $\varnothing$, Nygaard G, Nikolaou M (2010) Automatic control of managed pressure drilling. In: American control conference, Baltimore, MD, USA. https://doi.org/10.1109/acc.2010.5531008

32. Bryant TM, Grosso DS, Wallace SN (1991) Gas-influx detection with MWD technology. SPE Drill Eng 6:273-278. https://doi. org/10.2118/19973-PA

33. Bryant TM, Wallace SN (1991) Field results of an MWD acoustic gas influx detection technique. In: SPE/IADC drilling conference, Amsterdam, Netherlands. https://doi.org/10.2523/21963 -ms

34. Cadd M, Steven L, Graham R, Van Der Bos F, Aardolie N (2017) Integrating MPD into HPHT well planning synergies between MPD and HPHT. In: Abu Dhabi international petroleum exhibition \& conference, Abu Dhabi, UAE, 13-16 November 2017

35. Caetano E (1985) Upwind two-phase flow through an annulus. University of Tulsa, Tulsa 
36. Carbajal D, Burress C, Shumway B, Zhang Y (2009) Combining proven anti-sag technologies for HPHT north sea applications: clay-free oil-based fluid and synthetic, sub-micron weight material. In: SPE/IADC drilling conference, Amsterdam, The Netherlands. https://doi.org/10.2118/119378-ms

37. Carlsen LA, Nygaard G, Gravdal JE, Nikolaou M, Schubert J (2008) Performing the dynamic shut-in procedure because of a kick incident when using automatic coordinated control of pump rates and choke-valve opening. In: Society of petroleum engineers-SPE/IADC managed pressure drilling and underbalanced operations conference and exhibition 2008, pp 116-128. https://doi.org/10.2118/113693-ms

38. Cayeux E, Daireaux B, Dvergsnes EW, Scelevik G (2012) Early symptom detection on the basis of real-time evaluation of downhole conditions: principles and results from several north sea drilling operations. SPE Drill Complet 27:546-558. https:// doi.org/10.2118/150422-PA

39. Cenberlitas SA, Crenshaw JE, Gumus F, International W, Alpaugh K (2011) MPD technique in Haynesville shale delivers significant value in over pressured zones. In: AADE-11-NTCE-55

40. Choe J, Schubert JJ, Juvkam-Wold HC (2007) Analyses and procedures for kick detection in subsea mudlift drilling. SPE Drill Complet 22:296-303. https://doi.org/10.2118/87114-pa

41. Codazzi D, Till PK, Starkey AA, Lenamond CP, Monaghan BJ (1992) Rapid and reliable gas influx detection. In: IADC/SPE drilling conference, New Orleans, LA, USA, pp 793-800. https ://doi.org/10.2523/23936-ms

42. Culen MS, Brand PR, Bacon W, Gabaldon OR (2016) Evolution of the MPD operations matrix: the influx management envelope. In: SPE/IADC managed pressure drilling and underbalanced operations conference and exhibition, Galveston, Texas, USA. https://doi.org/10.2118/179191-ms

43. Das G, Das PK, Purohit NK, Mitra AK (1998) Rise velocity of a Taylor bubble through concentric annulus. Chem Eng Sci 53:977-993. https://doi.org/10.1016/S0009-2509(97)00210-8

44. Dashevskiy D, Dubinsky V, Macpherson JD (1999) Application of neural networks for predictive control in drilling dynamics. In: SPE annual technical conference and exhibition, Houston, Texas. https://doi.org/10.2523/56442-ms

45. Davoudi M, Smith JR, Patel BM, Chirinos JE (2011) Evaluation of alternative initial responses to kicks taken during managedpressure drilling. SPE Drill Complet 26:169-181. https://doi. org/10.2118/128424-PA

46. Dedenuola AD, Lyamu IE, Adeleye OA (2003) Stochastic approach to kick tolerance determination in risk based designs. In: Annual technical conference and exhibition, Denver, Colorado, USA. https://doi.org/10.2523/84174-ms

47. Dow B, Rojas F, Hobin J, Rojas J, Gallo F, Abuelaish A, Swaco M (2020) Managed pressure drilling —an unconventional efficiency tool applied in deepwater. In: Offshore technology conference, Houston, TX, USA, 4-7 May 2020

48. Driedger DJ, Kelly SP, Leggett C, Thain J, Silva M (2013) Managed pressure drilling technique applied in a Kurdistan exploration well. In: SPE Middle East oil and gas show and conference, Manama, Bahrain. https://doi.org/10.2118/164403-ms

49. Eaton AN, Beal LDR, Thorpe SD, Janis EH, Hubbell C, Hedengren JD, Nybø R, Aghito M, Bjørkevoll K, El Boubsi R, Braaksma J, Van Og G (2015) Ensemble model Predictive control for robust automated managed pressure drilling. In: Proceedings-SPE annual technical conference and exhibition, Houston, Texas, USA. https://doi.org/10.2118/174969-ms

50. Egbe $P$, Iturrios C (2020) Mitigating drilling hazards in a high differential pressure well using managed pressure drilling and cementing techniques. In: International petroleum technology conference, Dhahran, Saudi Arabia, 13-15 January 2020. https ://doi.org/10.2523/iptc-20180-ms
51. Elkatatny S, Tariq Z, Mahmoud M (2016) Real time prediction of drilling fluid rheological properties using artificial neural networks visible mathematical model (white box). J Pet Sci Eng 146:1202-1210. https://doi.org/10.1016/j.petrol.2016.08.021

52. Elmore RJ, Medley GH, Goodwin RC (2014) MPD techniques optimize HPHT well control. In: SPE annual technical conference and exhibition, Amsterdam, The Netherlands. https://doi. org/10.2118/170887-ms

53. Erge O, Ozbayoglu EM, Miska SZ, Yu M, Takach N, Saasen A, May R (2015) The effects of drillstring-eccentricity, -rotation, and -buckling configurations on annular frictional pressure losses while circulating yield-power-law fluids. In: SPE drilling and completion, Fort Worth, Texas, USA. https://doi. org/10.2118/167950-PA

54. Ettehadi Osgouei R, Ozbayoglu ME, Ozbayoglu MA, Yuksel $E$ (2010) Flow pattern identification of gas-liquid flow through horizontal annular geometries. In: SPE oil and gas india conference and exhibition, Mumbai, India. https://doi. org/10.2118/129123-ms

55. Fallah AH, Gu Q, Ma Z, Karimi Vajargah A, Chen D, Ashok P, van Oort E, May R (2019) An integrated thermal and multi-phase flow model for estimating transient temperature dynamics during drilling operations. In: SPE/IADC drilling conference, The Hague, The Netherlands. https://doi.org/10.2118/194083-ms

56. Feng J, Fu J, Chen P, Liu Z, Wei H (2015) Predicting pressure behavior during dynamic kill drilling with a two-phase flow. J Nat Gas Sci Eng 22:591-597. https://doi.org/10.1016/j.jngse .2015 .01 .006

57. Fjelde KK, Frøyen J, Ghauri AA (2016) A numerical study of gas kick migration velocities and uncertainty. In: Society of petroleum engineers-SPE Bergen one day seminar, Bergen, Norway. https://doi.org/10.2118/180053-ms

58. Fraser D, Lindley R, Moore D, Vander Staak M, Corp H (2014) Early kick detection methods and technologies. In: SPE annual technical conference and exhibition, Amsterdam, The Netherlands

59. Fredericks P, Reitsma D, Runggai T, Hudson N, Zaeper R, Backhaus O, Hernandez M (2008) Successful implementation of first closed loop, multiservice control system for automated pressure management in a shallow gas well offshore Myanmar. In: SPE/IADC drilling conference, Orlando, Florida, USA. https:// doi.org/10.2118/112651-ms

60. Fruhwirth RK, Thonhauser G, Mathis W (2006) Hybrid simulation using neural networks to predict drilling hydraulics in real time. In: SPE annual technical conference and exhibition, San Antonio, Texas, USA. https://doi.org/10.2523/103217-ms

61. Fu J, Su Y, Jiang W, Xiang X, Li B (2020) Multiphase flow behavior in deep water drilling: the influence of gas hydrate. Energy Sci Eng. https://doi.org/10.1002/ese3.600

62. Fu J, Su Y, Jiang W, Xu L (2015) Development and testing of kick detection system at mud line in deepwater drilling. J Pet Sci Eng 135:452-460. https://doi.org/10.1016/j.petrol.2015.10.013

63. Gedge B, Kaur H, Singh D, Refugio E, Quoc BT, Pacific WA, Minh HC (2013) Managed pressure drilling —a solution for drilling the challenging and un-drillable wells in Vietnam and South East Asia. In: SPE Asia Pacific oil \& gas conference and exhibition, Jakarta, Indonesia

64. Gidh Y, Purwanto A, Ibrahim H (2012) Artificial neural network drilling parameter optimization system improves ROP by predicting/managing bit wear. In: SPE intelligent energy international, Utrecht, The Netherlands. https://doi.org/10.2118/14980 1-ms

65. Gjønnes M, Myhre IG (2005) High angle HPHT wells. In: SPE Latin American and Caribbean petroleum engineering conference, Rio de Janeiro, Brazil. https://doi.org/10.2523/95478-ms 
66. Godhavn JM (2010) Control requirements for automatic managed pressure drilling system. SPE Drill Complet 25:336-345. https://doi.org/10.2118/119442-PA

67. Graham R, Geddes M, Harris T, Flaherty D, Shuttleworth N, McEwan B, Nordin N, Cadd M, O'Grady J, French P, Sandell R, Jeffries $S$ (2015) MPD technology used to deliver challenging HPHT drilling campaign. In: SPE offshore Europe conference and exhibition, Aberdeen, Scotland, UK, 8-11 September 2015. https://doi.org/10.2118/175479-ms

68. Gravdal JE, Lorentzen RJ, Fjelde KK, Vefring EH (2005) Tuning of computer model parameters in managed-pressure drilling applications using an unscented Kalman filter technique. In: Proceedings-SPE annual technical conference and exhibition, pp 4007-4015. https://doi.org/10.2523/97028-ms

69. Gravdal JE, Nikolaou M, Breyholtz $\varnothing$, Carlsen LA (2010) Improved kick management during MPD by real-time porepressure estimation. SPE Drill Complet 25:577-584. https://doi. org/10.2118/124054-PA

70. Grayson B (2009) Increased operational safety and efficiency with managed pressure drilling. In: SPE Americas $E$ and $P$ environmental and safety conference, San Antonio, Texas. https:// doi.org/10.2118/120982-ms

71. Gu Q, Fallah $A H$, Ambrus $A, M a Z$, Chen $D$, Ashok $P$, van Oort E (2019) A switching controller for mitigating riser gas unloading hazards in offshore drilling. In: SPE/IADC drilling conference, proceedings, 5-7 March, 2019. https://doi.org/10.2118/19416 3-pa

72. Guner H (2009) Simulation study of emerging well control methods for influxes caused by bottomhole pressure fluctuations during managed pressure drilling table of contents. Lousiana State University, Baton Rouge

73. Guo W, Honghai F, Gang L (2011) Design and calculation of a MPD model with constant bottom hole pressure. Pet Explor Dev 38:103-108. https://doi.org/10.1016/S1876-3804(11)60017 $-7$

74. Hannah KT, Gbenga M, Micheal I, Khalid O, Olaniyi O, James O (2019) Unconventional approach to managing kick during gas well drilling. In: SPE Nigeria annual international conference and exhibition 2019, NAIC 2019. Lagos, Nigeria, 5-7 August 2019. https://doi.org/10.2118/198845-MS

75. Hannegan DM (2011) Managed pressure drilling applications on offshore HPHT wells. In: Offshore technology conference, Houston, Texas, USA, 2-5 May. https://doi.org/10.4043/21208 -ms

76. Hargreaves D, Jardine S, Jeffryes B (2001) Early kick detection for deepwater drilling: new probabilistic methods applied in the field. In: SPE annual technical conference and exhibition, New Orleans, Louisiana, USA. https://doi.org/10.2523/71369 -ms

77. Hauge E, Aamo OM, Godhavn JM (2012) Model-based estimation and control of in/out-flux during drilling. In: Proceedings of the American control conference, pp 4909-4914. https://doi. org/10.1109/acc.2012.6315027

78. Hauge E, Aamo OM, Godhavn JM, Nygaard G (2013) A novel model-based scheme for kick and loss mitigation during drilling. J Process Control 23:463-472. https://doi.org/10.1016/j. jprocont.2013.01.006

79. He M, Liu G, Li J, Li J, Zhang T, Liu W, Li M (2015) Study of sour gas kicks taken during managed pressure drilling operations. In: SPE/IATMI Asia Pacific oil and gas conference and exhibition, Nusa Dua, Bali, Indonesia. https://doi.org/10.2118/176337-ms

80. Hernandez J, Arnone M, Valecillos J, Vives J, Vannoort R, Groves D, Hawthorn A (2019) Using managed pressure drilling and early kick/loss detection system to execute a challenging deepwater completions job in the Gulf of Mexico. In: IADC/ SPE managed pressure drilling and underbalanced operations conference and exhibition 2019, Amsterdam, The Netherlands, 09-10 April 2019. https://doi.org/10.2118/194554-ms

81. Hoberock LL, Stanbery SR (1981) Pressure dynamics in wells during gas kicks-2. Component models and results. JPT J Pet Technol 33:1367-1378. https://doi.org/10.2118/9822-pa

82. Holand P, Awan H (2012) Reliability of deepwater subsea BOP systems and well kicks. ExproSoft

83. Hollman L, Haq I, Christenson C, Da Silva TP, Ben Fayed MI, Thorn N, Geldof W (2015) Developing a MPD operation matrix-Case history. SPE/IADC Drilling Conference, Proceedings, 2015-January, pp 1284-1305. https://doi.org/10.2118/173094-ms

84. Hovland F, Rommetveit R (1992) Analysis of gas-rise velocities from full-scale kick experiments. In: SPE annual technical conference and exhibition, Washington, DC, USA. https://doi. org/10.2523/24580-ms

85. Hovland S, van Kuilenburg R, Drilling N, Eide T, Stridsklev C, Munro C (2019) Lessons learned with real integration of a deepwater MPD control system. In: IADC/SPE managed pressure drilling and underbalanced operations conference and exhibition, Amsterdam, The Netherlands, 09-10 April 2019. https://doi.org/10.2118/194543-ms

86. IADC (2011) UBO \& MPD glossary

87. Isambourg P, Bertin DL, Brangetto M (1999) Field hydraulic tests improve HPHT drilling safety and performance. SPE Drill Complet 14:219-227. https://doi.org/10.2118/59527-PA

88. Islam R, Khan F, Venkatesan R (2017) Real time risk analysis of kick detection: testing and validation. Reliab Eng Syst Saf 161:25-37. https://doi.org/10.1016/j.ress.2016.12.014

89. Jardine SI, White DB, Billingham J (1994) Computer-aided real-time kick analysis and control. SPE Drill Complet 9:199204. https://doi.org/10.2118/25711-pa

90. Jiang H, Liu G, Li J, Zhang T, Wang C (2020) Drilling fault classification based on pressure and flowrate responses via ensemble classifier in managed pressure drilling. J Pet Sci Eng 190:107126. https://doi.org/10.1016/j.petrol.2020.10712 6

91. Jiang H, Liu G, Li J, Zhang T, Wang C, Ling X (2018) An innovative diagnosis method for lost circulation with unscented Kalman filter. J Pet Sci Eng 166:731-738. https://doi.org/10.1016/j.petro I.2018.03.063

92. Jiang Y, Zhou Y, Liu W, Zhao Z, Cui T, Wang J (2014) The analysis of applications of micro-flux control drilling technology in narrow density window drilling scenarios. Procedia Eng 73:352361. https://doi.org/10.1016/j.proeng.2014.06.209

93. Johnson A, Piccolo B, Pinkstone H, Anderson B, Fraczek J (2017) Augmenting deepwater well control with managed pressure drilling equipment. In: SPE/IATMI Asia Pacific oil and gas conference and exhibition. https://doi.org/10.2118/186331-ms

94. Johnson AB, Cooper $S$ (1993) Gas migration velocities during gas kicks in deviated wells. in: SPE annual technical conference and exhibition, Houston, Texas, pp 177-185. https://doi. org/10.2523/26331-ms

95. Karimi Vajargah A, van Oort E (2015) Early kick detection and well control decision-making for managed pressure drilling automation. J Nat Gas Sci Eng 27:354-366. https://doi. org/10.1016/j.jngse.2015.08.067

96. Kelessidis VC, Dukler AE (1990) Motion of large gas bubbles through liquids in vertical concentric and eccentric annuli. Int J Multiph Flow 16:375-390. https://doi.org/10.1016/03019322(90)90070-Y

97. Khakzad N, Khan F, Amyotte P (2013) Quantitative risk analysis of offshore drilling operations: a Bayesian approach. Saf Sci 57:108-117. https://doi.org/10.1016/j.ssci.2013.01.022

98. Khakzad N, Khan F, Amyotte P (2013) Dynamic safety analysis of process systems by mapping bow-tie into Bayesian network. 
Process Saf Environ Prot 91:46-53. https://doi.org/10.1016/j. psep.2012.01.005

99. Khakzad N, Khan F, Amyotte P (2013) Dynamic safety analysis of process systems by mapping bow-tie into Bayesian network. Process Saf Environ, Prot

100. Kinik K, Gumus F, Osayande N (2015) Automated dynamic well control with managed-pressure drilling: a case study and simulation analysis. SPE Drill Complet 30:110-118. https://doi. org/10.2118/168948-PA

101. Kinik K, Gumus F, Osayande N (2014) A case study: first field application of fully automated kick detection and control by MPD system in western Canada. In: SPE/IADC managed pressure drilling and underbalanced operations conference and exhibition, Madrid, Spain

102. Lage ACVM, Nakagawa EY, Cordovil AGDP (1994) Experimental tests for gas kick migration analysis. In: SPE Latin American and Caribbean petroleum engineering conference, pp 617-624. https://doi.org/10.2523/26953-ms

103. Lage ACVM, Time RW (2000) An experimental and theoretical investigation of upward two-phase flow in annuli. In: SPE Asia Pacific oil and gas conference and exhibition, Brisbane, Australia, pp 325-336. https://doi.org/10.2118/79512-PA

104. Leblanc JL, Lewis RL (1968) A mathematical model of a gas kick. J Pet Technol 20:888-898. https://doi.org/10.2118/1860-pa

105. Li X, Guan C, Sui X, Gangtao (1998) New approach for early gas kick detection. In: International oil \& gas conference and exhibition in China, IOGCEC, pp 153-158. https://doi. org/10.2118/50890-ms

106. Liao Y, Wang Z, Pan D, Sun B, Duan W (2019) Gas kick simulation for offshore gas-hydrate reservoir drilling. In: Abu Dhabi international petroleum exhibition and conference 2019, ADIP 2019, Abu Dhabi, UAE. https://doi.org/10.2118/197358-ms

107. Lind YB, Kabirova AR (2014) Artificial neural networks in drilling troubles prediction. In: SPE Russian oil and gas exploration and production technical conference and exhibition, Moscow, Russia, pp 1243-1249. https://doi.org/10.2118/171274-ru

108. Ling K, He J, Ge J, Pei P, Shen Z (2015) A rigorous method to calculate the rising speed of gas kick. J Pet Explor Prod Technol 5:81-89. https://doi.org/10.1007/s13202-014-0111-4

109. Lordejani SN, Abbasi MH, Velmurugan N, Paristech M (2020) Modeling and numerical implementation of managed-pressure-drilling systems for the assessment of pressure-control systems. SPE Drill Complet. 1-22. https://doi-org.qe2a-proxy .mun.ca/10.2118/201108-PA

110. Ma Z, Karimi Vajargah A, Chen D, Van Oort E, May R, MacPherson JD, Becker G, Curry D (2018) Gas kicks in non-aqueous drilling fluids: a well control challenge. In: IADC/SPE drilling conference and exhibition, Texas, 6-8 March 2018

111. Mahdianfar H, Pavlov A, Aamo OM (2013) Joint unscented Kalman filter for state and parameter estimation in managed pressure drilling. 2013 European control conference, ECC 2013, pp 1645-1650. https://doi.org/10.23919/ecc.2013.6669753

112. Manikonda K, Hasan AR, Kaldirim O, Schubert JJ, Rahman MA (2019) Understanding gas kick behavior in water and oil-based drilling fluids. In: SPE Kuwait oil and gas show and conference 2019, KOGS 2019, Mishref, Kuwait, 13-16 October 2019

113. Mao Y, Zhang P (2019) An automated kick alarm system based on statistical analysis of real-time drilling data. In: Abu Dhabi international petroleum exhibition and conference 2019, Abu Dhabi, UAE, 11-14 November 2019

114. Vassallo M, Bernasconi G, Rampa V (2004) Bit bounce detection using neural networks. In: SEG Int'l exposition and 74th annual meeting, pp 14-17. https://doi.org/10.1007/s0042 1-009-1008-7

115. Mathew S, Nasr GG (2012) Optimized drilling by improved well control using MPD in narrow pressure window. In: SPE international production and operations conference and exhibition, Doha Qatar, 14-16 May 2012

116. Mathews J (1980) Upward migration of gas kicks in a shut-in well. Louisiana State University, Baton Rouge

117. Maus LD, Tannich JD, Ilfrey WT (1978) Instrumentation requirements for kick detection in deep water. In: Proceedings of annual offshore technology conference, 1978-May, pp 16331636. https://doi.org/10.4043/3240-ms

118. McKenzie M (1972) Factors affecting surface casing pressure during well control operations. Louisiana State University, Baton Rouge

119. Medina L, Baker J, Markabi M, Rojas J, Tarique Z, Dow B, Swaco M, Company S (2014) Automated MPD and an engineered solution: case histories from western Canada. In: IADC/SPE drilling conference and exhibition, Fort Worth, Texas, USA

120. Mehrabian A (2016) The stability of inclined and fractured wellbores. SPE J 21:1518-1536. https://doi.org/10.2118/180910-PA

121. MMS (2008) Notice to lessees and operators of federal oil, gas and sulphur leases in the outer continental shelf, Gulf of Mexico OCS region: managed pressure drilling projects

122. Moghazy S, van Noort R, Kozlov A, Haq I, Silva T, Hester C, Gabaldon O (2020) Using MPD and conventional methods to address a well control event in a deepwater exploration well. In: SPE/IADC drilling conference, Galveston, Texas, USA

123. Moosavinia M, Parker M, Alexandrov V, Palenov M (2016) Intelligent control for MPD. In: SPE/IADC managed pressure drilling and underbalanced operations conference and exhibition, Galveston, Texas, USA. https://doi.org/10.2118/180069-ms

124. Moran D, Ibrahim H, Purwanto A, Osmond J (2010) Sophisticated ROP prediction technologies based on neural network delivers accurate drill time results. In: IADC/SPE Asia Pacific drilling technology conference 2010, Ho Chi Minh City, Vietnam, pp 100-108. https://doi.org/10.2118/132010-ms

125. Motghare PD, Musale A (2017) Unconventional hydrocarbons: gas hydrates-drilling challenges and suitable technology. In: SPE oil and gas india conference and exhibition, Mumbai, India, pp 455-468. https://doi.org/10.2118/185424-ms

126. Nabiyev A, Nauduri S, Parker M, Fisher D, Cunningham D (2019) MPD called to a post well-control event to free a differentially stuck pipe. In: IADC/SPE managed pressure drilling and underbalanced operations conference and exhibition, Amsterdam, The Netherlands, 09-10 April 2019

127. Nandan A, Imtiaz S (2016) Nonlinear model predictive controller for kick attenuation in managed pressure drilling. IFACPapersOnLine 49:248-253. https://doi.org/10.1016/j.ifaco I.2016.07.268

128. Nandan A, Imtiaz S, Butt S (2015) Robust control of managed pressure drilling. In: 2014 Ocean.-St. John's, Ocean 2014, pp 1-8. https://doi.org/10.1109/OCEANS.2014.7003172

129. Nandan A, Imtiaz S, Butt S (2014) Control of bottomhole pressure in managed pressure drilling using IMC controller. In: Society of petroleum engineers-Arctic technology conference 2014, pp 584-590. https://doi.org/10.4043/24614-ms

130. Nas S (2012) Kick detection and well control in a closed wellbore. JPT J Pet Technol. https://doi.org/10.1071/aj10006

131. Nas S (2011) Kick detection and well control in a closed wellbore. In: Society of petroleum engineers-IADC/SPE managed pressure drilling and underbalanced operations conference and exhibition, pp 93-102. https://doi.org/10.1071/aj10006

132. Nas S (2010) Deepwater managed pressure drilling applications. In: CPS/SPE international oil \& gas conference and exhibition, Beijing, China, pp 8-10

133. Nas S, Toralde JS, Wuest C (2009) Offshore managed pressure drilling experiences in Asia Pacific. In: SPE/IADC drilling conference, Amsterdam, The Netherlands, pp 1099-1111. https://doi. org/10.2118/119875-ms 
134. Nhat DM, Venkatesan R, Khan F (2020) Data-driven Bayesian network model for early kick detection in industrial drilling process. Process Saf Environ Prot 138:130-138. https://doi. org/10.1016/j.psep.2020.03.017

135. Nickens HV (1987) A dynamic computer model of a kicking well. SPE Drill Eng. https://doi.org/10.2523/14184-ms

136. Nugroho WA, Hermawan S, Lazuardi BH, Mirza R (2017) Drilling problems mitigation in geothermal environment, case studies of stuck pipe and lost circulation. In: SPE/IATMI Asia Pacific oil and gas conference and exhibition, Jakarta, Indonesia, 17-19 October 2017. https://doi.org/10.2118/186922-ms

137. Nybø R, Bjørkevoll KS, Rommetveit R (2008) Spotting a false alarm-integrating experience and real-time analysis with artificial intelligence. In: Intelligent energy conference and exhibition, Amsterdam, Netherlands, pp 851-857. https://doi. org/10.2118/112212-ms

138. Nybø R, Sui $D$ (2014) Closing the integration gap for the next generation of drilling decision support systems. In: SPE intelligent energy international, Utrecht, The Netherlands, pp 497506. https://doi.org/10.2118/167864-ms

139. Okpo EE, Dosunmu A, Odagme BS (2016) Artificial neural network model for predicting wellbore instability. In: SPE Nigeria annual international conference and exhibition, Lagos, Nigeria. https://doi.org/10.2118/184371-ms

140. Onifade J, Patel B, Ertas E, Sammat E, Sahin B, Petroleum T (2015) Managed pressure drilling system provided value to offshore drilling variants of MPD technology. In: SPE/IADC managed pressure drilling and underbalanced operations conference and exhibition, Dubai, UAE

141. Ozbayoglu E, Miska S, Reed T, Takach N (2002) Analysis of bed height in horizontal and highly-inclined wellbores by using artificial neural networks. In: SPE international thermal operations and heavy oil symposium and international horizontal well technology conference, Calgary, Alberta, Canada. https:// doi.org/10.2523/78939-ms

142. Ozbayoglu EM, Osgouei RE et al (2012) Hole-cleaning performance of gasified drilling fluids in horizontal well sections. SPE J 23:267-273

143. Patil H, Deshpande K, Smelker K, Naphade P (2019) Understanding hydraulics and friction loss in extremely narrow annuli for deepwater MPD operations. In: SPE/IADC drilling conference, The Hague, The Netherlands, 5-7 March 2019. https://doi.org/10.2118/194177-ms

144. Pontes, T., Barbosa, F., Cosendey, S., 2018. Managed pressure drilling in deepwater Brazil presalt severe-loss scenario, in: SPE/ IADC Managed Pressure Drilling and Underbalanced Operations Conference and Exhibition. New Orleans, Louisiana, USA, 17-18 April 2018. https://doi.org/10.2118/189998-ms

145. Prairie G, Malik HK, Litwin RJ, Jones BC, Canada CCOP (2010) Successful use of managed pressure drilling (MPD) to counteract loss circulation and HP gas zones: a case study from red rock South Wapiti. In: Canadian unconventional resources \& international petroleum conference, Calgary, Alberta, Canada, 19-21 October 2010

146. Qutob H, Vieira P, Torres F, Arnone M (2011) Managed pressure drilling applications proves successful in the Middle East and North Africa Region. In: SPE/IADC Middle East drilling technology conference and exhibition, Muscat, Oman, pp 649-660. https://doi.org/10.2118/148534-ms

147. Rommetveit R (1995) Full scale kick experiments in horizontal wells. In: SPE annual technical conference and exhibition, Dallas, Texas, USA

148. Rader DW, Bourgoyne AT, Ward RH (1975) Factors affecting bubble-rise velocity of gas kicks. JPT J Pet Technol 27:571-584. https://doi.org/10.2118/4647-PA
149. Rajabi MM, Hannegan D, Moore D (2014) The MPD well control matrix: what is actually happening. In: SPE annual technical conference and exhibition, Amsterdam, The Netherlands, pp 1370-1385. https://doi.org/10.2118/170684-ms

150. Rajaieyamchee MA, Bratvold RB (2009) Real time decision support in drilling operations using Bayesian decision networks. In: SPE annual technical conference and exhibition, New Orleans, Louisiana, USA. https://doi.org/10.2118/124247-ms

151. Rehm B, Schubert J, Haghshenas A, Hughes J, Paknejad AS (2009) Managed pressure drilling, 1st edn. Gulf Publishing Company, Houston

152. Reitsma $D$ (2010) A simplified and highly effective method to identify influx and losses during managed pressure drilling without the use of a Coriolis flow meter. In: SPE/IADC managed pressure drilling and underbalanced operations conference and exhibition 2010, Kuala Lumpur, Malaysia. https://doi. org/10.2523/130312-ms

153. Reitsma DG, Couturier Y (2012) New choke controller for managed pressure drilling. IFAC Proc 1:223-230. https://doi. org/10.3182/20120531-2-NO-4020.00049

154. Roes V, Reitsma D, Smith L, McCaskill J, Hefren F (2006) First deepwater application of dynamic annular pressure control succeeds. In: SPE/IADC drilling conference, Miami, Florida, USA. https://doi.org/10.2523/98077-ms

155. Rostami SA, Brana J, Koithan T (2020) Integrated hydraulics modeling for managed pressure drilling. In: International petroleum technology conference 2020, IPTC 2020, Dhahran, Saudi Arabia, 13-15 January 2020. https://doi.org/10.2523/ iptc-19671-abstract

156. Safipour MJ, Mavaddat $Y$, Mavaddat $M, A^{\prime}$ Rabi M, Kadkhodaei N, Abdollahi A, Behbahani SMH (2017) Applicability of managed pressure drilling MPD in a high sulfur content fractured reservoir. In: SPE Abu Dhabi international petroleum exhibition and conference, Abu Dhabi, UAE, 13-16 November 2017. https ://doi.org/10.2118/188694-ms

157. Said MM, El-Sayed AAH (2018) The use of palm oil fatty acid methyl ester as a base fluid for a flat rheology high-performance drilling fluid. J Pet Sci Eng 166:969-983. https://doi. org/10.1016/j.petrol.2018.03.101

158. Salomone A, Burrafato $S$, Maccarini GR, Poloni R, Molaschi $C$, Huse A, Tangen GI, Regener T, Backhaus O, Grymalyuk S (2019) Kick isolation while drilling-first field test of an innovative risk mitigation technology. In: Abu Dhabi international petroleum exhibition and conference 2019, Abu Dhabi, UAE, 11-14 November 2019. https://doi.org/10.2118/197756-ms

159. Sammat E, Pavesi R, Besenzoni L, Copercini P (2013) Managed pressure drilling experience on deepwater application in West Africa. In: SPE/IADC drilling conference and exhibition, Amsterdam, The Netherlands, 5-7 March. https://doi. org/10.2118/163497-ms

160. Santos H, Leuchtenberg C, Shayegi S (2003) Micro-flux control: the next generation in drilling process for ultra-deepwater. In: Proceedings of the annual offshore technology conference, Port-of-Spain, Trinidad, West Indies. https://doi. org/10.4043/15062-ms

161. Santos OL, Bourgoyne AT (1989) Estimation of pressure peaks occurring when diverting shallow gas. In: Society of Petroleum Engineers, AIME, SPE DELTA. https://doi.org/10.2523/19559-ms

162. Santoyo E, Santoyo-Gutiérrez S, García A, Espinosa G, Moya SL (2001) Rheological property measurement of drilling fluids used in geothermal wells. Appl Therm Eng 21:283-302. https ://doi.org/10.1016/S1359-4311(00)00003-X

163. Saponja J, Adeleye A, Hucik B (2006) Managed-pressure drilling (MPD) field trials demonstrate technology value. In: SPE/ IADC drilling conference, Miami, Florida, USA. https://doi. org/10.2523/98787-ms 
164. Scoular T, Global BP, Organization W, Hathaway KL, Essam W, Costa KK, Johnson SA, Rawcliff A, Phillips AW, Burton D (2012) Utilizing MPD to drill HPHT deepwater exploration well. In: SPE/ IADC managed pressure drilling and underbalanced operations conference and exhibition, Milan, Italy, 20-21 March 2012

165. Shaker SS, Reynolds DJ, Services GA (2020) Kicks and blowouts prediction before and during drilling in the over-pressured sediments introduction. In: Offshore technology conference originally, Houston, TX, USA, 4-7 May 2020

166. Siahaan HB, Jin H, Safonov MG (2012) An adaptive PID switching controller for pressure regulation in drilling. IFAC Proc 1:90-94. https://doi.org/10.3182/20120531-2-NO-4020.00017

167. Singh HKD, Quoc BT, Yong TC, Van Khanh D, Cuong NX, Tung HT, Nam TH, Hai NH, Tuan DA, Bao TN, Hung TN, Cuong NPH (2018) Application of managed pressure drilling on a semisubmersible tender-assisted rig to address drilling challenges in HPHT gas condensate wells, offshore Vietnam. In: SPE Asia Pacific oil and gas conference and exhibition, Brisbane, Australia, 23-25 October 2018. https://doi.org/10.2118/191927-ms

168. Skalle P, Podio AL, Tronvoll J (1991) Experimental study of gas rise velocity and its effect on bottomhole pressure in a vertical well. In: Offshore Europe conference, Aberdeen, United Kingdom. https://doi.org/10.2523/23160-ms

169. Skogdalen JE, Utne IB, Vinnem JE (2011) Developing safety indicators for preventing offshore oil and gas deepwater drilling blowouts. Saf Sci 49:1 187-1199. https://doi.org/10.1016/j. ssci.2011.03.012

170. Smith JR, Patel BM (2012) A proposed method for planning the best initial response to kicks taken during managed-pressuredrilling operations. SPE Drill Complet 27:194-203. https://doi. org/10.2118/143101-PA

171. Smith JR, Patel BM (2011) A proposed method for planning the best response to kicks taken during managed pressure drilling operations. In: IADC/SPE managed pressure drilling and underbalanced operations conference and exhibition, Denver, Colorado, USA. https://doi.org/10.2118/143101-ms

172. Song L, Hu W, Li K, Wang X, Song L (2019) Application of model-free adaptive control in managed pressure drilling. In: Proceedings of 2018 IEEE international conference of safety produce informatization, IICSPI 2018, pp 102-107. https://doi. org/10.1109/IICSPI.2018.8690445

173. Spivey BJ, Payette GS, Wang L, Bailey JR, Sanderson D, Lai SW, Charkhand B, Eddy A (2017) Challenges and lessons from implementing a real-time drilling advisory system. In: Proceedings-SPE annual technical conference and exhibition. https:// doi.org/10.2118/0218-0049-jpt

174. Starkey C, Webre T, Rafferty M, Fredericks P, Hobin J (2016) MPD application for ultra-HPHT wellbore. In: SPE/IADC managed pressure drilling and underbalanced operations conference and exhibition, Galveston, Texas, USA. https://doi. org/10.2118/179184-ms

175. Stokka SI, Andersen JO, Freyer J, Welde J (1993) Gas kick warner-an early gas influx detection method. In: SPE drilling conference, Amsterdam, Netherlands. https://doi. org/10.2523/25713-ms

176. Stone CR, Tian S (2009) Hydraulic parameters of underbalanced and managed-pressure drilling. J Pet Technol 61:59-62. https ://doi.org/10.2118/0209-0059-jpt

177. Sule I, Khan F, Butt S, Yang M (2018) Kick control reliability analysis of managed pressure drilling operation. J Loss Prev Process Ind 52:7-20. https://doi.org/10.1016/j.jlp.2018.01.007

178. Sun K, Wu L, Bui N, Samuel R (2017) Leak off test LOT modeling for inclined and horizontal wells. In: SPE annual technical conference and exhibition, San Antonio, Texas, USA, 9-11 October 2017, pp 1-17. https://doi.org/10.2118/187326-ms
179. Sun X, Sun B, Gao Y, Wang Z, Liao Y, Yu X (2018) Transient fully coupled hydrodynamic-hydrate model for deepwater kick simulation. In: Offshore technology conference Asia, Kuala Lumpur, Malaysia. https://doi.org/10.4043/28342-ms

180. Sunthankar A (2000) Study of the flow of aerated drilling fluids in annulus under ambient temperature and pressure conditions. University of Tulsa, Tulsa

181. Swanson BW, Gardner AG, Brown NP, Murray PJ (1997) Slimhole early kick detection by real-time drilling analysis. SPE Drill Complet 12:27-32. https://doi.org/10.2118/25708-PA

182. Szczepanski R, Yerlett TK, Brown NP, Hamilton TAP (1998) Differences between methane and condensate kicks-a simulation study. SPE Drill Complet 13:36-41. https://doi. org/10.2118/37366-PA

183. Tarvin JA, Hamilton AP, Gaynord PJ, Lindsay GD (1994) Gas rises rapidly through drilling mud. In: IADC/SPE drilling conference, Dallas, Texas, USA, pp 637-649. https://doi. org/10.2523/27499-ms

184. Tellez CP, Duno H, Casanova O, Colombine W, Lupo C, Palacios $J R$, Medina L (2009) Successful application of MPD technique in a HP/HT well focused on performance drilling in Southern Mexico deep fractured carbonates reservoirs. In: IADC/SPE managed pressure drilling and underbalanced operations conference and exhibition, San Antonio, Texas. https://doi. org/10.2118/122200-ms

185. Teoh M, Moghazy S, Smelker K, Van Noort R, Valecillos JC, Hernandez J, Arnone M, Krietemeyer L (2019) Managed pressure cementing MPC within a narrow pressure window, deepwater Gulf of Mexico application. In: IADC/SPE managed pressure drilling and underbalanced operations conference and exhibition, Amsterdam, The Netherlands, 09-10 April 2019. https://doi.org/10.2118/194536-ms

186. Tian S, Medley G, Stone CR, Corp SE (2007) Parametric analysis of MPD hydraulics. In: IADC/SPE managed pressure drilling and underbalanced operations conference and exhibition, Galveston, Texas, USA

187. Todorov D, Thonhauser G (2014) Hydraulic monitoring and well control event detection using model based analysis. In: Proceedings of the annual offshore technology conference, vol 2, pp 1156-1163. https://doi.org/10.2118/0914-0144-jpt

188. Torsvik A, Skogestad JO, Linga H (2017) An experimental study of gas influx in oil-based drilling fluids for improved modeling of high-pressure, high-temperature wells. SPE Drill Complet 32:245-254. https://doi.org/10.2118/178860-pa

189. Tost BC, Rose K, Carney J, Aminzadeh F, Suhag A (2020) Early kick detection from downhole measurements: a novel method for reducing the frequency and magnitude of loss-of-well-control events. In: Offshore technology conference, Houston, TX, USA, 4-7 May 2020. https://doi.org/10.4043/30831-ms

190. Tseytlin S (2013) Methods and devices for determination of gas-kick parameters and prevention of well explosion. In: SPE Arctic and extreme environments conference and exhibition, AEE 2013, Moscow, Russia. https://doi.org/10.2118/166871-ru

191. Van Riet EJ, Reitsma D, Vandecraen B (2003) Development and testing of a fully automated system to accurately control downhole pressure during drilling operations. In: SPE/IADC Middle East drilling technology conference \& exhibition, Abu Dhabi, UAE, pp 181-192. https://doi.org/10.2118/85310-ms

192. Vefring EH, Wang Z, Gaard S, Bach GF (1995) Advanced kick simulator for high angle and horizontal wells-part I. In: SPE/ IADC drilling conference, Amsterdam, Netherlands, pp 123-134

193. Vieira P, Arnone M, Russel B, Cook I, Moyse K, Torres F, Qutob $H$, Yuesheng C, Qing C (2008) Constant bottomhole pressure: managed-pressure drilling technique applied in an exploratory well in Saudi Arabia. In: SPE/IADC managed pressure drilling 
and underbalanced operations conference and exhibition, Abu Dhabi, UAE, pp 546-559. https://doi.org/10.2118/113679-ms

194. Vieira P, Arnone M, Torres F, Barragan F (2009) Roles of managed pressure drilling technique in kick detection and wellcontrol-the beginning of the new conventional drilling way. In: PE/IADC Middle East drilling technology conference and exhibition, Manama, Bahrain, pp 116-125. https://doi. org/10.2118/124664-ms

195. Wang Y, Salehi S (2015) Drilling hydraulics optimization using neural networks. In: PE digital energy conference and exhibition, The Woodlands, Texas, USA, pp 319-331. https://doi. org/10.2118/173420-ms

196. Wang Z, Peden JM, Lemanczyk RZ (1994) Gas kick simulation study for horizontal wells. In: IADC/SPE drilling conference, Dallas, Texas, USA, pp 625-632. https://doi.org/10.2523/27498-ms

197. Wang ZY, Sun BJ (2014) Deepwater gas kick simulation with consideration of the gas hydrate phase transition. J Hydrodyn 26:94-103. https://doi.org/10.1016/S1001-6058(14)60011-1

198. Watson D, Brittenham T, Moore PL (2003) Advanced well control. Society of Petroleum Engineers

199. Wei N, Sun W, Meng Y, Zhou S, Li G, Guo P, Dong K, Li Q (2016) Sensitivity analysis of multiphase flow in annulus during drilling of marine natural gas hydrate reservoirs. J Nat Gas Sci Eng 36:692-707. https://doi.org/10.1016/j.jngse.2016.11.007

200. Wylie WW, Visram AS (1990) Drilling kick statistics. In: IADC/SPE drilling conference, Houston, Texas, USA, pp 77-88. https://doi. org/10.2523/19914-ms

201. Xu J, Ding C, Wang S, Qi B (2014) The prediction of pressure, temperature, velocity, and density of two-phase flow in shut-in procedures for the HTHP gas wells. Pet Sci Technol 32:335-344. https://doi.org/10.1080/10916466.2011.590837

202. Xu Y, Guan Z, Xu C, Zhang H, Zhang H (2015) Risk evaluation methods of gas hydrate when shallow strata drilling in deepwater area. In: Proceedings of the annual offshore technology conference, vol 2, pp 921-933. https://doi.org/10.4043/25727 -ms

203. Xu Z, Song X, Li G, Zhu Z, Zhu B (2019) Gas kick simulation in oil-based drilling fluids with the gas solubility effect during high-temperature and high-pressure well drilling. Appl Therm Eng 149:1080-1097. https://doi.org/10.1016/j.appltherma leng.2018.12.110

204. Yang M, Zhao X, Meng Y, Li G, Zhang L, Xu H, Tang D (2017) Determination of transient temperature distribution inside a wellbore considering drill string assembly and casing program. Appl Therm Eng 118:299-314. https://doi.org/10.1016/j.applt hermaleng.2017.02.070
205. Yin H, Liu P, Li Q, Wang Q, Gao D (2015) A new approach to risk control of gas kick in high-pressure sour gas wells. J Nat Gas Sci Eng 26:142-148. https://doi.org/10.1016/j.jngse.2015.06.014

206. Yin Q, Yang J, Li Z, Huang Y (2020) A field case study of managed pressure drilling in offshore ultra high-pressure high-temperature exploration well in the South China Sea. SPE J 27-29. https://doi-org.qe2a-proxy.mun.ca/10.2118/191060-PA

207. Zan K, Bickel JE (2014) Managed pressure drilling probabilistic risk analysis: an illustration. In: Offshore technology conference, Houston, Texas, pp 2238-2249. https://doi.org/10.4043/25290 -ms

208. Zein J, Irawan F, Hidayat AM, Amin RAM (2016) Case studyconstant bottom hole pressure of managed-pressure drilling surface back pressure in managed-pressure drilling. In: SPE Asia Pacific oil \& gas conference and exhibition, Perth, Australia, 25-27 October 2016, pp 1-10

209. Zhong Y, Liu Y, Lin X, Luo S (2016) The method of oilfield development risk forecasting and early warning using revised Bayesian network. Math Probl Eng. https://doi. org/10.1155/2016/9564801

210. Zhou H, Fan H, Wang H, Niu X, Wang G (2018) A novel multiphase hydrodynamic model for kick control in real time while managed pressure drilling. In: SPE/IADC Middle East drilling technology conference and exhibition, Abu Dhabi, UAE, 29-31 January 2018

211. Zhou J, Krstic M (2016) Adaptive predictor control for stabilizing pressure in a managed pressure drilling system under timedelay. J Process Control 40:106-118. https://doi.org/10.1016/j. jprocont.2016.01.004

212. Zhou J, Nygaard G, Godhavn JM, Breyholtz $\varnothing$, Vefring EH (2010) Adaptive observer for kick detection and switched control for bottomhole pressure regulation and kick attenuation during managed pressure drilling. In: Proceedings of the 2010 American control conference, ACC 2010, pp 3765-3770. https://doi. org/10.1109/acc.2010.5531551

213. Zhou J, Stamnes ØN, Aamo OM, Kaasa GO (2011) Switched control for pressure regulation and kick attenuation in a managed pressure drilling system. IEEE Trans Control Syst Technol 19:337-350. https://doi.org/10.1109/TCST.2010.2046517

Publisher's Note Springer Nature remains neutral with regard to jurisdictional claims in published maps and institutional affiliations. 